NBER WORKING PAPER SERIES

\title{
COMMUNICATION AND BARGAINING BREAKDOWN:
} AN EMPIRICAL ANALYSIS

\author{
Matthew Backus \\ Thomas Blake \\ Jett Pettus \\ Steven Tadelis \\ Working Paper 27984 \\ http://www.nber.org/papers/w27984 \\ NATIONAL BUREAU OF ECONOMIC RESEARCH \\ 1050 Massachusetts Avenue \\ Cambridge, MA 02138 \\ October 2020
}

We are grateful to numerous seminar and conference participants, as well as to Charles Angelucci, Anne Bartel, Wouter Dessein, Liran Einav, Sarah Moshary, Michaela Pagel, Andrea Prat, and especially Jonah Rockoff for thoughtful comments, as well as many eBay employees for their input and support, and finally Brenden Eum and Alphonse Simon for excellent research assistance; all remaining errors are our own. Part of this research was supported by NSF Grant SES-1629060. Matt Backus has in the past been a paid consulting researcher for eBay Inc. The views expressed herein are those of the authors and do not necessarily reflect the views of their employers, eBay, or the National Bureau of Economic Research.

NBER working papers are circulated for discussion and comment purposes. They have not been peer-reviewed or been subject to the review by the NBER Board of Directors that accompanies official NBER publications.

(C) 2020 by Matthew Backus, Thomas Blake, Jett Pettus, and Steven Tadelis. All rights reserved. Short sections of text, not to exceed two paragraphs, may be quoted without explicit permission provided that full credit, including $\odot$ notice, is given to the source. 
Communication and Bargaining Breakdown: An Empirical Analysis

Matthew Backus, Thomas Blake, Jett Pettus, and Steven Tadelis

NBER Working Paper No. 27984

October 2020

JEL No. C78,D82,D83,M21

\section{$\underline{\text { ABSTRACT }}$}

Bargaining breakdown-whether as delay, conflict, or missing trade—plagues bargaining in environments with incomplete information. Can a bargaining environment that facilitates or restricts communication alleviate these costs? We exploit a unique opportunity to study this question using real market transactions: eBay Germany's Best Offer platform. On May 23, 2016, the platform introduced unstructured communication allowing buyers and sellers on the desktop version of the site, but not the mobile app, to accompany price offers with a message. Using this natural experiment, our difference-in-differences approach documents a $14 \%$ decrease in the the rate of breakdown among compliers. Though adoption is immediate, the effect is not. We show, using text analysis, that the dynamics are consistent with repeat players learning how to use communication in bargaining, and that the messaging strategies of experienced sellers are correlated with successful bargaining.

Matthew Backus

Graduate School of Business

Columbia University

3022 Broadway, Uris Hall 619

New York, NY 10027

and NBER

matthew.backus@columbia.edu

Thomas Blake

eBay Research Labs

2065 Hamilton Ave

San Jose, CA 94125

tomblake@gmail.com
Jett Pettus

Columbia University

jettpettus@gmail.com

Steven Tadelis

Haas School of Business

University of California, Berkeley

545 Student Services Building

Berkeley, CA 94720

and NBER

stadelis@haas.berkeley.edu 


\section{Introduction}

Bargaining is the mechanism of choice for many of our most important transactions: peace negotiations, federal budgets and the formation of governing coalitions, allocation of refugees, the sale of a business, the purchase of a car, child care duties, and the number of bedtime stories, to name a few. Yet at least since Myerson and Satterthwaite (1983), economists have understood the potential for failure in bargaining. When parties to a negotiation do not know each other's reservation values, each has an incentive to overstate the strength of their position to get a better deal, sometimes resulting in costly delays, and other times in a complete loss of socially beneficial trades. In this spirit, Crawford (1982) posits that "the potential welfare gains from improving the efficiency of bargaining outcomes are enormous, perhaps even greater than those that would result from a better understanding of the effects of macroeconomic policy."

We consider an open question in this domain: does communication improve the efficiency of bargaining outcomes, or is it all "cheap talk?" Charness (2012) writes:

For many, the word bargaining conjures an image of people sitting around a table talking. Yet communication is one of the least understood facets of bargaining. Most economic models of bargaining assign no role for communication beyond conveying offers or their acceptability. But clearly, communication does a lot more than that.

He continues, presciently, "this area should be of great importance in the coming years, particularly given the strong trend to virtual interaction in bargaining." Here, we offer evidence on this question using data from such a virtual bargaining platform: eBay's Best Offer bargaining marketplace. We present two main findings: first, we document a statistically and economically significant positive relationship between the availability of free-form text communication and bargaining success. Second, applying text analysis techniques to users' messages, we document a convergent pattern which, we argue, represents repeat players learning how to communicate in the bargaining protocol. We show that this pattern is related to experience, and that the strategies adopted by experienced bargainers are correlated with successful negotiation. This is consistent with prior findings in experimental work demonstrating that beyond the ability to communicate, the content of communication matters as well for bargaining

outcomes. Our work is, to the best of our knowledge, the first study of the role of communication in bargaining using data from real-world bargaining interactions. 
Our findings relate to a broader debate concerning the restriction of communication in bargaining which, in practice, is quite common. A high stakes example from international relations is "shuttle diplomacy," which played a high-profile role in many negotiation episodes in the twentieth century. Theoretical models of such mediation, itself a medium of communication, focus on the informational role of these restrictions, as against the theoretical limitations of baseline of unverifiable cheap talk (Fey and Ramsay, 2010; Hörner et al., 2015). Yet these theoretical limitations offer limited perspective on real-world bargaining, which is rife with cheap talk (very little of which, in our setting, resembles meaningful exchange of information).

This is particularly salient for marketplaces, where bargaining is increasingly commonplace. eBay's Best Offer bargaining platform, which allows sellers to receive and respond to offers from potential buyers, accounts for approximately $10 \%$ of eBay's trade volume, which was $\$ 84$ billion globally in $2016 .{ }^{1}$ On the Chinese platform TaoBao, which hosted trade volumes of $\$ 115$ billion in 2016, bargaining is the standard for all transactions. ${ }^{2}$ And in, in 2014, Amazon.com introduced their own bargaining mechanism for the Amazon Marketplaces platform called "Make an Offer." All of these platforms face the question of how and whether to regulate communication.

Our setting is the Best Offer bargaining platform on eBay.de, the German counterpart of eBay.com. ${ }^{3}$ Sellers who create a listing on the website may enable Best Offer, a free feature that allows buyers to make offers below the listing price. An offer may be countered, and the counter-offer countered, etc., yielding a protocol very similar to sequential, alternating-offers bargaining (Rubinstein, 1982). Originally, eBay.de did not allow communication, and only numerical offers were relayed between the parties. ${ }^{4}$ However, in a policy change that took effect May 23, 2016, offers could be accompanied by a 250-character message when made from the eBay.de website. Importantly, the change did not affect buyers who made offers using their mobile devices. The sudden nature of the change and its incomplete coverage affords us a natural experiment to study the role of communication in bargaining.

\footnotetext{
${ }^{1}$ See Backus et al. (2020) and eBay's 2016 10k SEC filing.

${ }^{2}$ On TaoBao, communication is encouraged between buyers and sellers on an instant messenger service. This has been cited as a factor in their success over the Chinese equivalent of eBay (Oberholzer-Gee and Wulf, 2009).

${ }^{3}$ This platform is also used in Gizatulina and Gorelkina (2017), who conduct a field experiment selling gift cards on the platform to study surplus division.

${ }^{4}$ We believe this has to do with the origins of eBay.de, which was originally developed by Rocket Internet SE in 1999 and then sold to eBay.com. Thanks to Ariel Stern for pointing this out.
} 
We find that, while the typical bargaining session in our sample was successful fortyfour percent of the time, bargainers who used messages were eight percentage points more likely to transact than they would have been in the absence of communication. This corresponds to a fourteen percent reduction in the rate of bargaining breakdown. We do not observe bargainers' private values, so "breakdown" is not the same as inefficiency (e.g., if a seller values the product more than the buyer, then breakdown is an efficient outcome). Therefore our computation is conservative in the sense that the denominator is too large - the decrease in the rate of inefficient breakdown is likely to be much larger. Additionally, examining week-specific effects, we find that the effect of communication grows gradually over the four weeks after introduction. One mechanism that may drive this pattern is that it takes time for players to learn how to best make use of the new feature after the change.

To explore this mechanism, we implement a descriptive analysis of the content of the communications. Most notably, we offer evidence that over the weeks following the introduction of communication, sellers' communication strategies evolve as they learn to use the communication feature in bargaining. In contrast, the content of buyers' communications is largely random, which is consistent with our intuition, and their behavior on eBay, that they are occasional, short-run players. We show that not only are repeat sellers' strategies changing over time, but that they are convergent, supporting the hypothesis that they are learning. Consistent with this, we show that messages most similar to the endpoint of that convergence are more likely to succeed, with a magnitude that is remarkably close to our estimates of the treatment effect on the treated from the introduction of messaging. We also, in an Appendix, borrow tools from text analysis to learn about what sellers are converging to; though this analysis is entirely descriptive, the findings are consistent with behavioral and experimental work which shows that cost-based rationales are effective, and overly effusive communication strategies can be counterproductive.

Turning to prior work, our paper is the first, to the best of our knowledge, to study the role of communication on bargaining using real-world bargaining interactions. There is, however, substantial prior theoretical and experimental work. Surveying theoretical contributions, Crawford (1990) distinguishes between tacit and explicit models of bargaining, where tacit models leave no role for communication. All of noncooperative bargaining theory is tacit; it abstracts away from talk to focus on actions: offers, counteroffers, delay, agreement, and exit. For practitioners, however, 
haggling and negotiation are understood as communication, which may explain the minor role of economic theory in negotiation coursework among students of law and business. More recent work studies explicit bargaining, in which communication is modeled as cheap talk. ${ }^{5}$ There is significant disagreement on the efficiency of allowing cheap talk: theoretical work predicts that, among rational actors, it is at best irrelevant, and possibly detrimental to bargaining efficiency. ${ }^{6}$ In the latter case restricting communication is a form of pre-commitment, which may improve outcomes.

In contrast, experimental work has found potential for communication to improve outcomes in bargaining among other games. ${ }^{7}$ Indeed, bargaining experiments that manipulate the availability of communication (Radner and Schotter, 1989; Valley et al., 2002) offer evidence that communication may permit bargaining efficiency that exceeds the theoretical upper bounds outlined by Myerson and Satterthwaite (1983). However, these results have not been validated in the field, and subsequent extensions are not uniformly positive: Ert et al. (2014) construct an experimental scenario with misalignment of incentives, similar to bargaining over lemons, where communication elicits skepticism and increases breakdown; Bolton et al. (2003) and McGinn et al. (2012) highlight drawbacks of communication in bargaining games with more than two players, and Lee and Ames (2017) and Jeong et al. (2019) show how the content of the messages can facilitate or inhibit negotiations.

Communication is of interest for antitrust economics, where colluding parties have to bargain over the division of surplus. Cooper and Kühn (2014) experimentally study the role of communication in repeated Prisoners' Dilemma games; Awaya and Krishna (2015) show how cheap-talk communication can overcome the problem of secret price cuts in collusive arrangements, and Harrington and Ye (2019) show how cheap-talk

\footnotetext{
${ }^{5}$ This literature typically appends a cheap-talk "pre-game" to an existing bargaining model. See, e.g., Farrell and Gibbons (1989), Cabral and Sákovics (1995), for early examples, and Menzio (2007) for a formalization of partially directed search in models of cheap-talk wage-posting.

${ }^{6}$ See Goltsman et al. (2009) for a treatment and review of communication and bargaining in the cheap-talk setting described by Crawford and Sobel (1982), and, in the legal literature, Brown and Ayres (1994) and Ayres and Nalebuff (1997).

${ }^{7}$ In experiments mirroring Crawford and Sobel (1982), Cai and Wang (2006) find that subjects consistently reveal "too much" information to be rationalized by equilibrium behavior. This is consistent with lie aversion (Gneezy, 2005; Gibson et al., 2013) and guilt aversion (Charness and Dufwenberg, 2006, 2011), as well as communication fostering other-regarding preferences (Coffman and Niehaus, 2020). Crawford et al. (2013) argue that it is consistent with level-K thinking, even in the absence of preferences for truthfulness, as L0 types anchor on the truth. In games with multiple equilibria, communication helps coordination on better outcomes (Cooper et al., 1992; Blume and Ortmann, 2007; Ellingsen and Östling, 2010). McGinn et al. (2003) offer evidence for this mechanism by showing that communication elicits dyadic strategies by bargainers.
} 
communication among sellers in an upstream market can facilitate collusion when the downstream market is characterized by negotiations, as in many intermediate goods markets. Clark and Houde (2014) offer an empirical example of the role of communication in collusion, studying the collapse of a cartel resulting from antitrust enforcement equipped with a wire tap in Quebec. Moreover, in a setting that features on-path bargaining breakdown but not communication, Loertscher and Marx (2020) show how mechanism design can be used to understand bargaining and countervailing power in antitrust.

Finally, our work contributes to the literature on learning in strategic settings. Empirical work in this area is particularly scarce because there are few opportunities to observe the introduction of a novel mechanism in a continuously operating marketplace. In this respect, our work is related to Doraszelski et al. (2017), who document bidding behavior in a newly opened electricity auction market. Our exercise builds on the recent introduction of text analysis and natural language processing; see Gentzkow et al. (2019a) for a survey. For the same reason that we need new tools to study text - that messages live in a high-dimensional space - we conjecture that it is a natural environment to study learning and experience. ${ }^{8}$

Section 2 describes the eBay.de platform, and Section 3 describes the dataset and explain the motivation for the sample design. Section 4 offers a discussion of identification and our main causal estimates of the effect of communication on bargaining breakdown. Section 5 presents a descriptive analysis of the text communication itself in order to match the patterns we find, and Section 6 shows that our text analysis findings are consistent with message-level regressions predicting successful bargaining. Finally, Section 7 concludes with a brief discussion of the implications for platforms and future directions for empirical work on communication and bargaining.

\footnotetext{
${ }^{8}$ Though no prior work isolates the interaction of communication and experience in bargaining, there is evidence of the importance of experience in bargaining: see, e.g. Card and Dahl (2012), who documented the role of expertise in bargaining agents in arbitration, and Backus et al. (2020), who found effects of experience on bargaining outcomes on eBay.com.
} 
Figure 1: Example of a Best Offer Listing

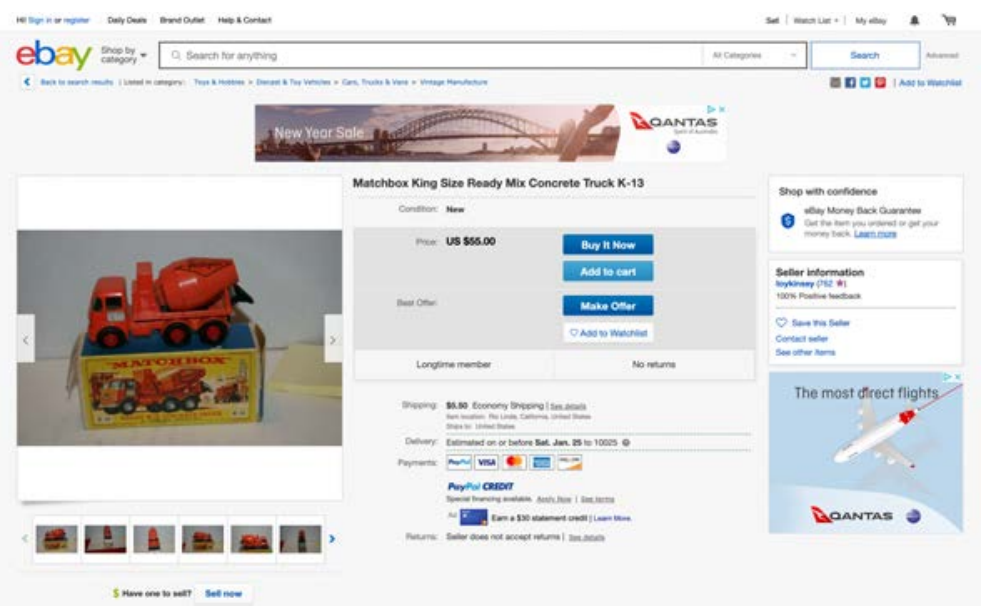

Notes: This is an example View Item page for a Best-Offer enabled listing. A buyer may purchase at the asking price of $\$ 55$ by clicking the Buy-It-Now button, or they may engage in bargaining by clicking the Make Offer button.

\section{Our Empirical Setting: Bargaining on eBay.de}

\subsection{Best Offer Bargaining}

eBay's online platform matches buyers to sellers who sell products ranging from art and collectibles to mobile phones, with over $\$ 95$ billion dollars in gross merchandise volume worldwide in 2018. The platform operates in many markets throughout the world, the largest by revenue are the US (eBay.com) and Germany (eBay.de). ${ }^{9}$

Sellers who list an item choose either an auction or fixed-price ("Buy-it-Now") format. We focus on a subset of fixed-price listings for which the seller enables the "Best Offer" bargaining feature as shown in Figure 1. A buyer considering this listing has two options to purchase the good: they can either purchase at the posted asking price (here, $\$ 55$ ), or they can offer to purchase at a lower price. If the buyer makes an offer, the seller is notified and they may then accept, decline, or make a counter-offer. If the seller makes a counter-offer, the buyer may accept, decline, or make a counter-offer, and so on, in the spirit of Rubenstein-Stähl alternating, sequential-offers bargaining. Offers by either party expire automatically after 48 hours. ${ }^{10}$

\footnotetext{
${ }^{9}$ Figure and revenue ranking based on eBay's 2018 Annual Report.

${ }^{10}$ For a more thorough descriptive characterization of the Best Offer environment, see Backus et al. (2020). Data from that study, which are collected from the US site eBay.com, are publicly available at http://www.nber.org/data/bargaining/.
} 
Figure 2: Messages and Best Offer

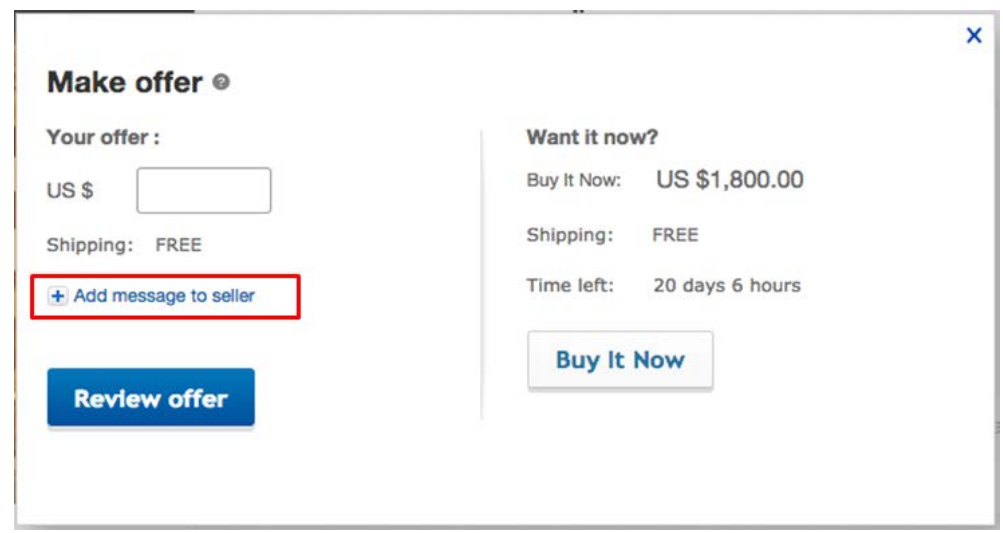

(a) eBay.com

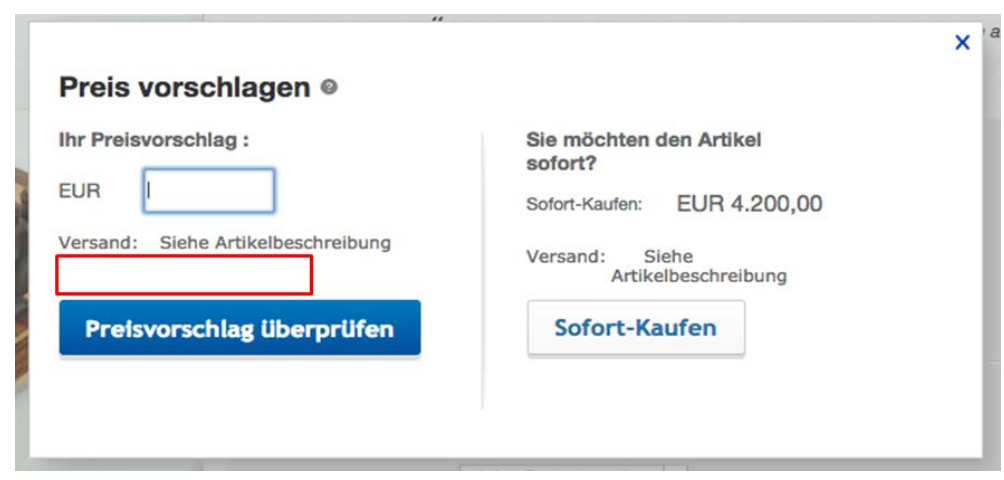

(b) eBay.de (before May 23, 2016)

Notes: Panel (a) depicts the "Make Offer" panel for eBay.com, the US site, where we have highlighted the "add message to seller" button. Panel (b) depicts the pre-treatment panel on eBay.de, where there is no option to send a message.

The Best Offer bargaining mechanisms on eBay.com and eBay.de are mostly identical except for one peculiarity that was unique to eBay.de up until the policy change we study: bargainers weren't allowed to communicate like on eBay.com. Figure 2(a) depicts the "Make Offer" interface through which buyers submit their offer, for eBay.com. If a buyer clicks the "add message to seller" button, they may include a free-form text message of up to 250 characters which will accompany their offer. Figure 2(b) depicts the parallel "Preis Vorschlagen" interface, for eBay.de. The red rectangle highlights where the missing option to send a message might have been. ${ }^{11}$

\footnotetext{
${ }^{11}$ The reason for the difference is unclear, but it may be a historical artifact: eBay.de is the successor of Alando.de, a clone of eBay.com created by the company Rocket Internet in 1999. 100 days after its creation, it was sold to eBay for $\$ 43$ million. Thanks to Ariel Stern of HBS for pointing this out.
} 


\subsection{The Policy Change: May 23, 2016}

On May 23, 2016, the "add a message to seller" feature was added to eBay.de's Best Offer bargaining platform. However, the rollout on that date was partial. The website eBay.de was updated, but the app for mobile users was not.

The policy change affords the main source of variation that we will exploit in this paper. Unlike many changes to the eBay platform, the introduction of messaging on eBay.de was not accompanied by a far-reaching "seller update", and no other major changes to the eBay.de experience happened around this change. Moreover, the availability of an untreated group in the post period (mobile users) affords us a control group in order to separate changes in behavior from a secular trend.

\section{Dataset and Sample Design}

We obtained proprietary data from eBay itself to evaluate the effect of messaging on bargaining breakdown. We study bargaining interactions, which we define as a buyer-item pair in which we observe at least one offer. Our main dataset includes all interactions for which the first buyer offer was made during an eight-week window between April 26, 2016 and June 20, 2016, constructed to be four weeks before and four weeks after the introduction of messaging on May 23, 2016.

\subsection{Summary Statistics}

Table 1 presents summary statistics for the main sample across several dimensions: listings, buyers, sellers, and interactions. This sample includes 3.3 million interactions involving 2.2 million unique listings, 444 thousand sellers, and 1.6 million buyers. The listings span all categories of eBay excluding real estate, automobiles, and tickets. As documented by Backus et al. (2020), Best Offer is more frequently used in categories with substantial heterogeneity, such as Collectibles. Listings observed in our sample have on average 1.5 interactions (note that our sample excludes listings with zero interactions) and the distribution is highly skew: 79 percent have only one; 91 percent 
have two or fewer, 96 percent have three or fewer, and there is a right tail with many more. $^{12} 55$ percent ultimately sell through the Best Offer mechanism. ${ }^{13}$

Both buyers and sellers may be involved in multiple interactions - on average, 2.1 and 7.4, respectively. In both cases there is substantial positive skew, suggesting a large right-tail of highly-active participants. On the buyer side, this derives from the fact that most $(60 \%)$ are only observed in a single interaction, while the top decile participates in four or more interactions. On the seller side, only $34 \%$ of the sample is observed only once, while the top decile participates in twelve or more interactions. This difference motivates our interpretation of buyers as short-run players and sellers as long-run players. These patterns hold for sales and purchases as well.

At the interaction level, which is the unit of observation for the empirical analysis that follows, we see that $44 \%$ of interactions end in a sale. These facts are consistent with findings in prior work using data from the U.S. site eBay.com (Backus et al., 2019, 2020). The final two interaction-level variables of Table 1 are of unique interest to this paper: interactions may be initiated by buyers using the desktop version of eBay $(54 \%)$ or the mobile version (46\%), which is important because only desktop buyers have the opportunity to send messages after the policy change. Finally, $50 \%$ of our sample falls after the policy change on May 23, 2016.

\subsection{Additional Controls}

In addition to the basic characteristics summarized in Table 1, we have a number of controls available to predict bargaining breakdown. These include the asking price of the seller; dummy variables by product category and condition (new, used, refurbished, or unknown); and dummy variables for the day of the week on which the first offer in an interaction is made (to allow for differential behavior on weekends and weekdays); a "holiday" dummy, which encodes all publicly observed holidays in Germany, as there is a particularly large number of them in May. ${ }^{14}$ We also include controls for the weather in Frankfurt, Hesse, which we expect to be correlated with weather elsewhere

\footnotetext{
${ }^{12}$ Partly for this reason, and partly because Best Offer listings tend to take longer to sell than, say, auctions, we ignore the possibility of competing offers by buyers. This is intuitive, since sellers also have the option to hold an auction on the eBay platform.

${ }^{13}$ Listings that sold at the Buy-it-Now price are not classified as an interaction because no negotiation is involved. These sales do not appear in our dataset.

${ }^{14}$ Publicly observed holidays in our sample include: May 1, Labor day; May 5, Ascension Day; May 8, Mother's Day; May 16, Whit Monday, and May 26, Corpus Christi.
} 
Table 1: Summary Statistics

\begin{tabular}{lccccc}
\hline \hline & Mean & Std. Dev. & Skewness & Min & Max \\
\hline Listing-Level Data & & & & & \\
\hline Asking Price (USD) & 100.6 & 151.5 & 2.889 & 1.050 & 999.9 \\
Number of Interactions & 1.490 & 2.566 & 82.62 & 1 & 1004 \\
$\mathbb{1}($ Sold) & 0.563 & & & & \\
$\quad$ N & 2210575 & & & & \\
\hline Seller-Level Data & & & & & \\
\hline Number of Interactions & 7.426 & 42.30 & 47.81 & 1 & 7142 \\
Number of Sales & 3.279 & 20.76 & 44.17 & 0 & 3115 \\
$\quad \mathrm{~N}$ & 443644 & & & & \\
\hline Buyer-Level Data & & & & & 396 \\
\hline Number of Interactions & 2.101 & 3.102 & 20.24 & 1 & 389 \\
Number of Purchases & 0.928 & 1.526 & 25.26 & 0 & \\
$\quad \mathrm{~N}$ & 1567995 & & & & \\
\hline Interaction-Level Data & & & & & \\
\hline Number of Offers & 1.873 & 1.116 & 1.535 & 1 & 6 \\
$\mathbb{1}$ (Ended in Sale) & 0.442 & & & & \\
$\mathbb{1}$ (Buyer on Desktop) & 0.537 & & & & \\
$\mathbb{1}$ (First offer after May 23) & 0.501 & & & & \\
$\quad \mathrm{~N}$ & 3294362 & & & & \\
\hline \hline
\end{tabular}

Notes: This table presents summary statistics for the main dataset of Best Offer interactions taking place within an eight-week window, four weeks before and four weeks after the policy change on May 23, 2016. Fixing that set of interactions, we have constructed the summary statistics four ways: where the unit of observation is the listing (i.e., the product), the buyer, the seller, or the interaction itself.

in Germany, as weather conditions are both serially correlated and anecdotally cited as affecting online activity. These include a dummy for precipitation as well as the deviation of temperature from a linear trend over the sample.

\subsection{Adoption on May 23, 2016}

As depicted in Figure 3(a), users adopted messages rapidly: within days, the hazard rate with which bargaining interactions by desktop-only buyers involved messaging stabilized at approximately six percent. Both panels in Figure 3 distinguish between the case where the buyer is either exclusively making offers from a desktop computer or exclusively making offers from a mobile device. We do this because there was initially no messaging feature for the eBay.de mobile app. Therefore in Panel (a), which plots the hazard rate at which interactions involve any message (both seller and buyer messages), the hazard rate for the case where the buyer is on the mobile app is much lower. These are exclusively messages sent by sellers, to mobile-only buyers who 
Figure 3: Launch of Messaging Feature

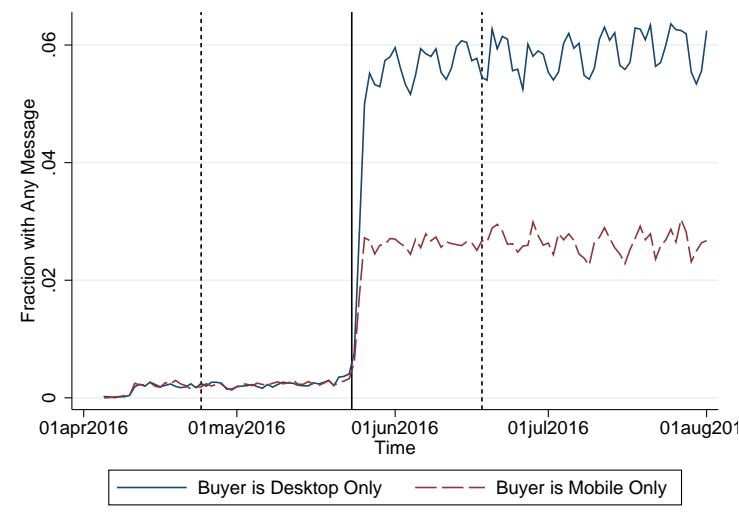

(a) Any Message

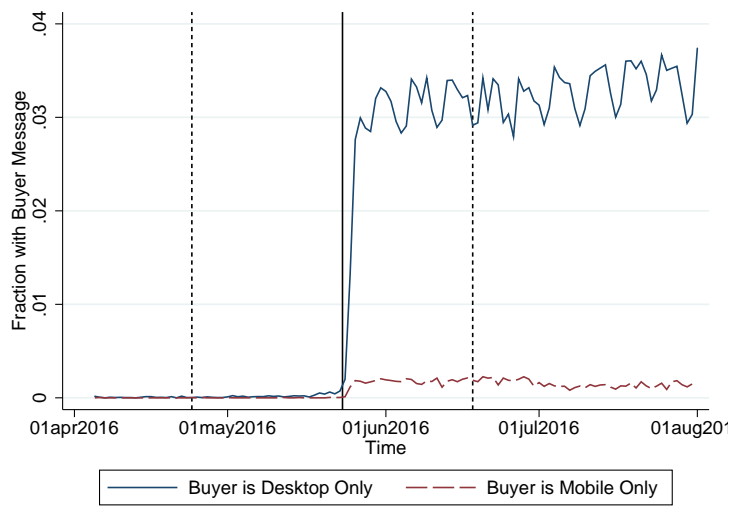

(b) Buyer Message

Notes: Panel (a) depicts the fraction of interactions, by first offer date, in which a message was included by the seller. Panel (b) restricts attention to cases where the message was sent by a buyer. Both panels split the sample by whether the buyer was active on the desktop or mobile version of the platform. The solid vertical line represents the policy change. Dashed vertical lines depict the bounds of the eight-week window, centered at launch, of our main sample.

cannot read them. In Panel (b), we plot the hazard rate of buyer messages, which confirms that mobile-only buyers are not sending messages after the change. ${ }^{15}$

\section{The Effect of Introducing Communication on the Likelihood of Bargaining Breakdown}

\subsection{Empirical Design and Identification}

\subsubsection{OLS and Endogeneity}

Our identification strategy is meant to circumvent the most salient problem, that the choice to include a message is endogenous. In particular, we expect a negative bias: that bargainers send messages for goods of a type where bargaining is least likely to succeed, or in order to motivate a particularly aggressive offer.

We illustrate this by estimating a linear probability model, the details of which can be found in Appendix Section A. The unconditional correlation between the

\footnotetext{
${ }^{15}$ About $0.1 \%$ of offers per day included messages prior to the feature launch, and similarly there are cases where mobile-only buyers appear to send messages. In the former case, these are seller-side only, and rarely in German, so we believe that they are anomalies related to sellers registered on multiple sites. In the latter, we believe that these are simple database errors.
} 
presence of a message and bargaining success is negative, but once we condition on the log of the asking price it is small and positive. This reflects the fact that bargaining interactions with messages tend to involve goods that are more expensive than bargaining interactions that do not, and that bargaining success is less likely for more expensive products, as documented by Backus et al. (2020) for eBay.com.

We expect this problem to be at least as important for unobservable characteristics than the asking price, and therefore rely on the policy change for a natural experiment and a more credible estimate of the effect of communication on bargaining breakdown.

\subsubsection{Identification}

The variation generated by the May 23, 2016 policy change allows us to identify the effect of communication in two ways. The first is a simple pre-post design studying the change in the mean success rate of bargaining interactions before and after the policy change among desktop users. Our dependent variable is $\mathbb{1}$ (success), a dummy for whether the bargaining interaction ends in a sale. Let $X$ denote a set of controls, $P$ (alternatively, "post") a dummy equal to one if the first offer in an interaction is in the post period, and $D$ (alternatively, "desktop") a dummy equal to one if the buyer makes offers from the desktop version of eBay.de. Then, the pre-post estimate of the effect of communication on bargaining success is given by:

$$
\hat{\beta}_{\mathrm{pp}}^{C}=\mathbb{E}[\mathbb{1}(\text { success }) \mid X, P=1, D=1]-\mathbb{E}[\mathbb{1}(\text { success }) \mid X, P=0, D=1] .
$$

We can then use the untreated set of buyers who made offers on the mobile

platform - where messaging was unavailable both before and after May 23, 2016 - to control for common trends and alleviate concerns of endogeneity. This suggests a differences-in-differences design:

$$
\begin{aligned}
\hat{\beta}_{\mathrm{dd}}^{C}= & (\mathbb{E}[\mathbb{1}(\text { success }) \mid X, P=1, D=1]-\mathbb{E}[\mathbb{1}(\text { success }) \mid X, P=0, D=1]) \\
& -(\mathbb{E}[\mathbb{1}(\text { success }) \mid X, P=1, D=0]-\mathbb{E}[\mathbb{1}(\text { success }) \mid X, P=0, D=0]) .
\end{aligned}
$$

Both of the above strategies identify an effect that should be interpreted as an intent to treat (ITT) estimate, i.e., an estimate of the effect of the availability of communication, rather than the effect of actually choosing to communicate. In order 
Table 2: Complier Characteristics

\begin{tabular}{lccc}
\hline \hline & $\mathbb{P}(x=1)$ & $\mathbb{P}(x=1 \mid$ complier $)$ & $\frac{\mathbb{P}(x=1 \mid \text { complier })}{\mathbb{P}(x=1)}$ \\
\hline Ask Price in $(\$ 0, \$ 50)$ & 0.52 & 0.41 & 0.78 \\
Ask Price in $[\$ 50, \$ 150)$ & 0.27 & 0.29 & 1.08 \\
Ask Price in $[\$ 150, \$ 250)$ & 0.09 & 0.11 & 1.30 \\
Ask Price $\geq \$ 250$ & 0.12 & 0.19 & 1.54 \\
Friday, Saturday, or Sunday & 0.42 & 0.42 & 1.00 \\
Precipitation & 0.46 & 0.67 & 1.46 \\
Holiday & 0.10 & 0.03 & 0.32 \\
Post & 0.50 & 1.00 & 2.00 \\
Desktop & 0.54 & 1.00 & 1.86 \\
\hline \hline
\end{tabular}

Notes: This table summarizes complier characteristics, i.e. the characteristics of interactions in the treatment group that "comply" and involve a message between bargainers. Each row represents a dummy variable which is taken to be $x$ in the column formulas above.

to identify the treatment effect on the treated (TOT), we need to clarify who the compliers, i.e., those we actually consider to be treated, are.

\subsubsection{ITT and TOT: Who are Compliers?}

We say that a bargaining interaction is in the ITT group if the first offer occurs after May 23, 2016 and if the buyer uses the desktop version of eBay.de. Not every such interaction involves a message. By definition, compliers are interactions in our ITT group in which a message is sent by either party. Some messages were sent outside of this group, e.g., when a seller sends a message to a buyer who is using the mobile app. We exclude these for two reasons: first, because the buyer was mechanically unable to read the message, and second, because it turns out that using this less-restrictive definition will cause us to overstate the magnitude of the TOT estimate. ${ }^{16}$

Table 2 summarizes the characteristics of the compliers. Of particular note is the fact that bargainers are more likely to send messages when the asking price is higher, consistent with the intuition that communication is costly. The higher likelihood of precipitation and lower likelihood of a holiday is due mostly to early-May holidays and late-May rains, and we note that weekend users are no more likely to send messages. ${ }^{17}$

\footnotetext{
${ }^{16}$ Results are available on demand from the authors, however the intuition is simple: including messages in the pre-period or mobile set but not in the intent-to-treat group will inflate the coefficients on $\mathbb{1}$ (Post) and $\mathbb{1}$ (Desktop), respectively, and thereby depress the coefficient on $\mathbb{1}$ (Post). $\mathbb{1}$ (Desktop). Since the first-stage coefficient (which is in the denominator) is smaller, the IV effect will be inflated. Including all non-ITT messages will approximately double the estimate.

${ }^{17}$ We group Friday, Saturday, and Sunday based on the OLS coefficients reported in Table A-1, where weekends appear to be discretely different from weekdays.
} 
Figure 4: Predicted Success Rates

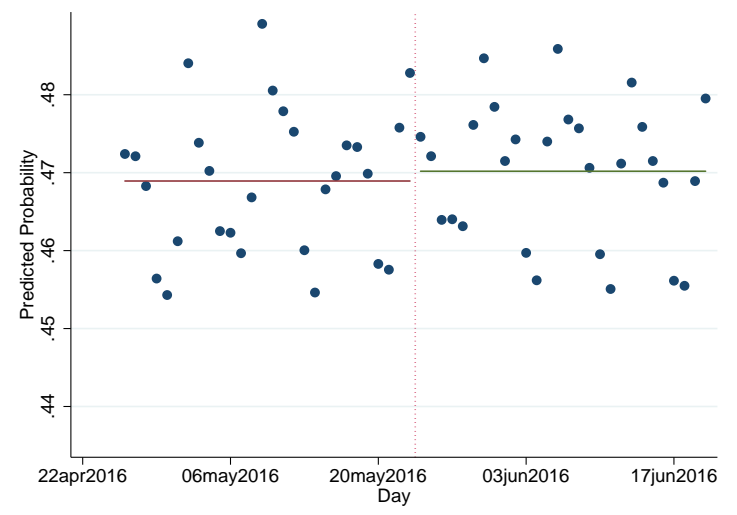

(a) Desktop

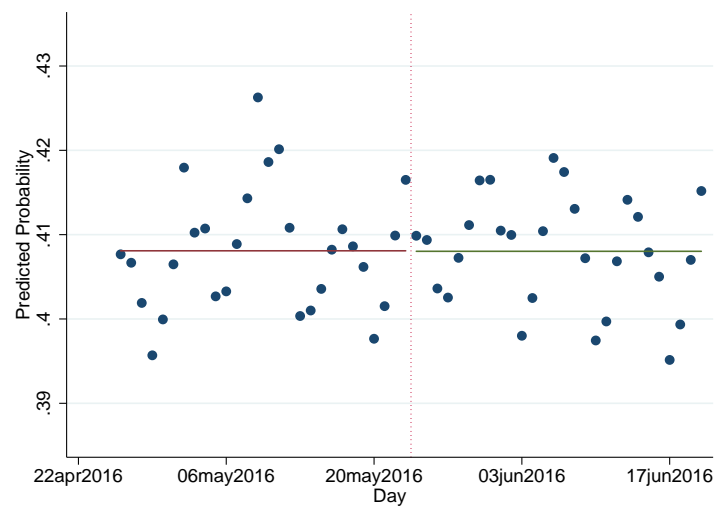

(b) Mobile

Notes: Panel (a) depicts predicted success rates using a large set of controls (ln(ask price); category by condition fixed effects; day of week, precipitation, and holiday dummies and the temperature) for desktop users only. Panel (b) replicates this for the mobile users. The vertical axes on both plots are scaled identically subject to a location shift.

It is natural to wonder whether despite our controls, unobservable characteristics of the listings are generating compositional differences in the periods before and after the change. Therefore, in Figure 4 we document the predicted success rate conditional on those controls for all interactions for both samples - mobile and desktop - where the first-stage regression excludes the dummy for treatment as well as the time trend. We see a small change in the predicted likelihood of success for desktop users and none for mobile users, so we anticipate slightly smaller effects when we include controls.

\subsection{Empirical Results}

\subsubsection{Regression Analysis}

In what follows, we first generate precise estimates $\hat{\beta}_{p p}^{C}$ and $\hat{\beta}_{d d}^{C}$, and second, we identify a treatment effect on the treated because, recall from Figure 3, only a small fraction of interactions in the post period involve a message. To accomplish the former, we reformulate (1) and (2) in terms of a linear probability model and estimate them using OLS (in all of what follows we omit observation indices):

$$
\mathbb{1}(\text { success })=\beta_{p p}^{0}+X \beta_{p p}^{1}+P \beta_{p p}^{C}+\varepsilon,
$$

and

$$
\mathbb{1}(\text { success })=\beta_{d d}^{0}+X \beta_{d d}^{1}+P \beta_{d d}^{2}+D \beta_{d d}^{3}+P D \beta_{d d}^{C}+\varepsilon .
$$


Next we consider the treatment effect on the treated. We estimate this by reformulating (4) as an instrumental variables regression:

$$
\mathbb{1}(\text { success })=\beta_{i v}^{0}+X \beta_{i v}^{1}+P \beta_{i v}^{2}+D \beta_{i v}^{3}+\mathbb{1}(\text { complier }) \beta_{i v}^{C}+\varepsilon,
$$

where $P \cdot D$ is an instrument for $\mathbb{1}$ (complier), and $\mathbb{1}$ (complier) is a dummy for interactions in the ITT group that include a message. Importantly, this does not employ any variation that is not already used in the differences-in-differences estimator. Instead, it just rescales the estimate to the end of interpreting its economic meaning. As with all estimates of the treatment effect on the treated, it should be interpreted with caution, as bargainers' decision of whether to send a message is endogenous.

Results for each of these three estimators, both with and without the controls discussed in Section 2, are presented in Table 3. We see a large effect of the policy change on success for desktop users, 0.46 percentage points in model (1), which is attenuated by the inclusion of controls to a statistically insignificant effect of 0.23 percentage points in model (2). As we show in the next section, the control that attenuates the result is the time trend. In the post period, there is a substantial positive drift, which stabilizes after a few weeks. Is this a delayed treatment effect, or a secular trend on the platform? To distinguish between these hypotheses, we need a suitable control group; here, interactions involving buyers who use the mobile app.

Critically, as we see in models (3) and (4), our estimates of $\beta_{p p}^{C}$ for the placebo sample of mobile users are very close to zero. Therefore, differences in differences estimates in models (5) and (6), where the relevant estimate is the term on the interaction effect, are of the same order as those in (1): we estimate effects of 0.40 and 0.42 , respectively. In particular for specification (6), with the rich set of controls, the mobile group is distinguishing common time trend from the ITT estimate.

Finally, models (7) and (8) report the IV estimates which are rescaled to obtain the TOT estimate. As only a small fraction of users, approximately six percent, actually send messages in the post period, this means that the roughly half-percent effect on conversion for the Best Offer environment at large translates to a substantially larger and economically important effect on the treated. To be precise, versus a baseline probability of success near $44 \%$ for the full sample (from Table 1), interactions that involve messages in the treated group are 7.44 (or 7.73, with controls) percentage points more likely to succeed. The inclusion of these controls (time trend; $\ln$ (ask price); category by condition fixed effects; day of week, precipitation, and holiday dummies 
and the temperature) allows us to rule out the most salient alternative hypotheses by which the effect is driven by compositional changes spurred by the introduction of communication, e.g. if messaging prompts buyers to bargain over cheaper goods which also have lower rates of breakdown. This leaves is with our main result: a $14 \%$ decrease in the rate of bargaining breakdown among the compliers.

Finally, a note on size and power: we are looking at extremely small effects, on the order of half a percentage point. They are small because take-up of the messaging feature among the ITT group, i.e., the compliance rate, is low, at approximately six percent. While we have a lot of data in our main sample-3.41 million bargaining interactions - this turns out to be close to what we need. Simple power calculations for the detection of an effect of 0.005 with a baseline success rate of 0.442 (borrowed from Table 1) with a confidence of $\alpha=0.05$ and a power of fifty percent implies that we need a dataset of 2.72 million experimentally generated observations equally divided between treated and not. Therefore there are limitations on how far we can push the data to understand heterogeneity in the effects of communication.

While the low compliance rate is, in that sense, an empirical challenge, there is also a sense in which it is an advantage of our environment. If the greater fraction of buyers sent messages - and those messages were important for bargaining - then their communication might have an equilibrium effect on the quantity, composition, or listing style of goods on the platform. In the language of Angrist et al. (1996), these are concerns about the stable unit treatment value assumption (SUTVA) - i.e., that treatment of some observations has spillover effects on the effectiveness of the treatment for others. The fact that the compliance rate is very low reassures us that they are not economically significant, and that we can identify a partial equilibrium effect, i.e. conditional on the broader state of eBay.de in the Summer of 2016.

\subsubsection{Graphical Intuition}

In order to offer some intuition for the results in Table 3, Figure 5 presents the data aggregated to the daily level, both with and without residualization on a large set of controls. ${ }^{18}$ In both cases we see an apparent jump in the success rate of approximately

\footnotetext{
${ }^{18}$ Note that while we will include it in the regression analysis that follows, we have excluded a time trend from the set of controls here. Coefficients from the OLS regression that generates these residuals are reported in model (6) of Table A-1 in the appendix, where we present OLS results as a straw man alternative to our empirical design.
} 


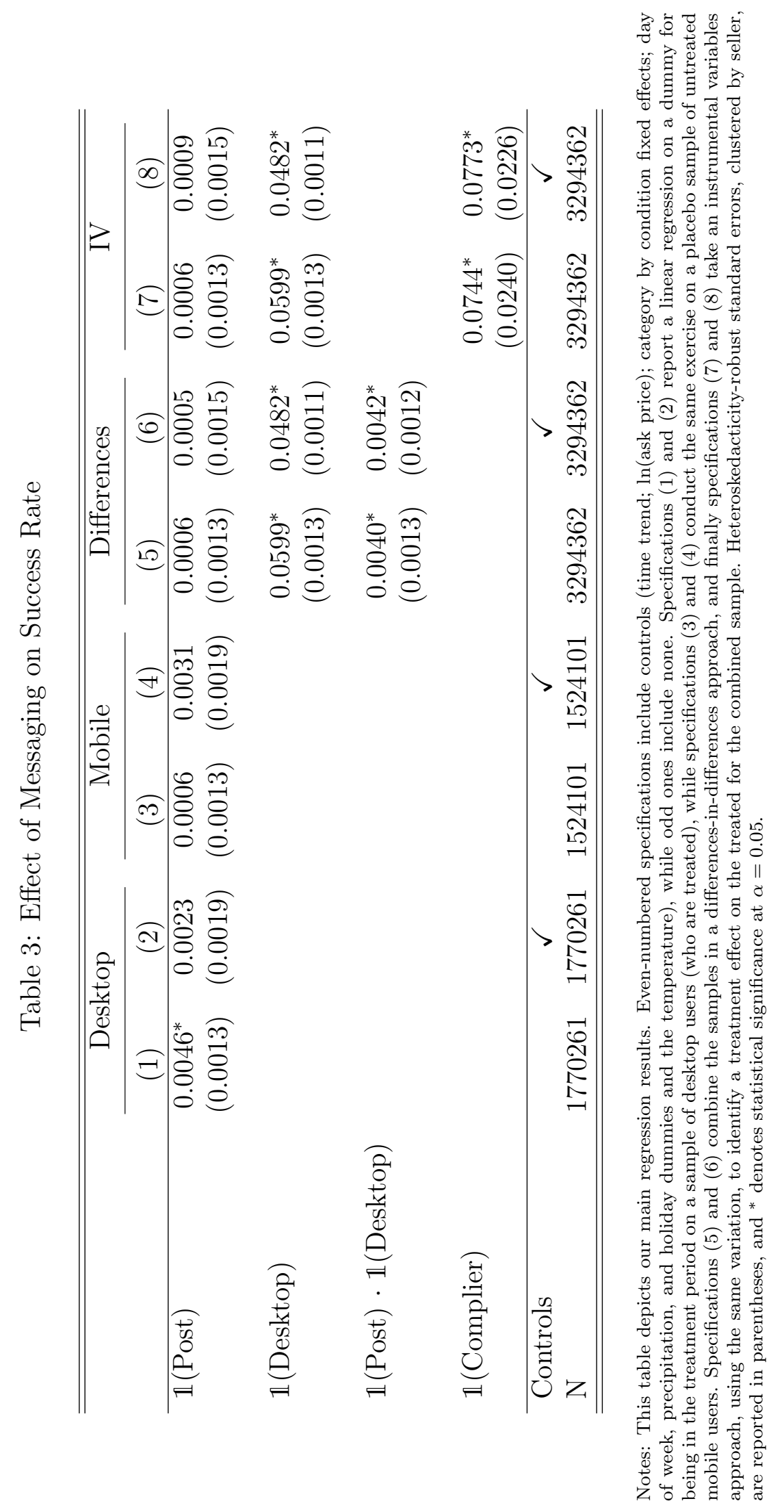


Figure 5: Bargaining Success Rates

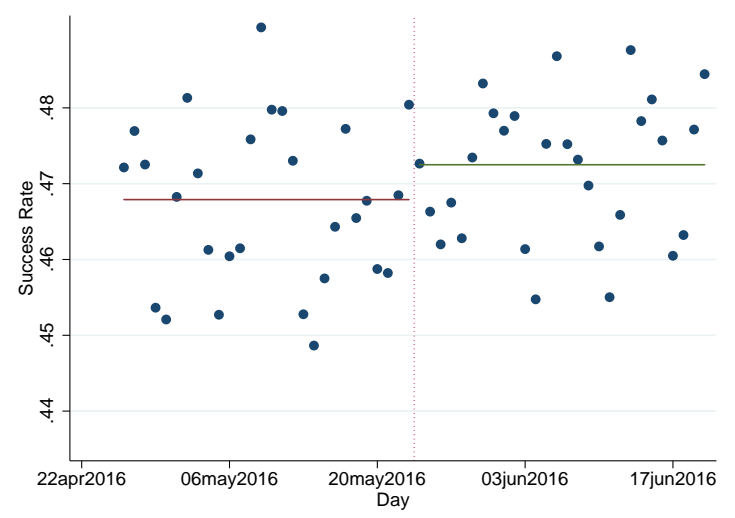

(a) Desktop: Raw

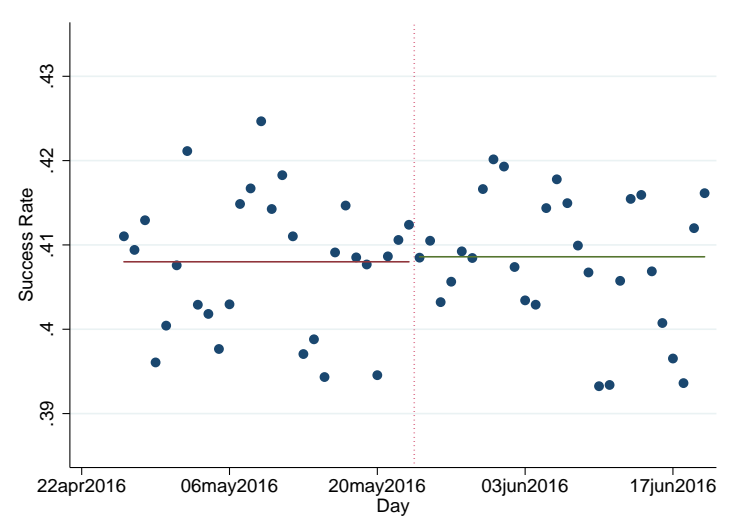

(c) Mobile: Raw

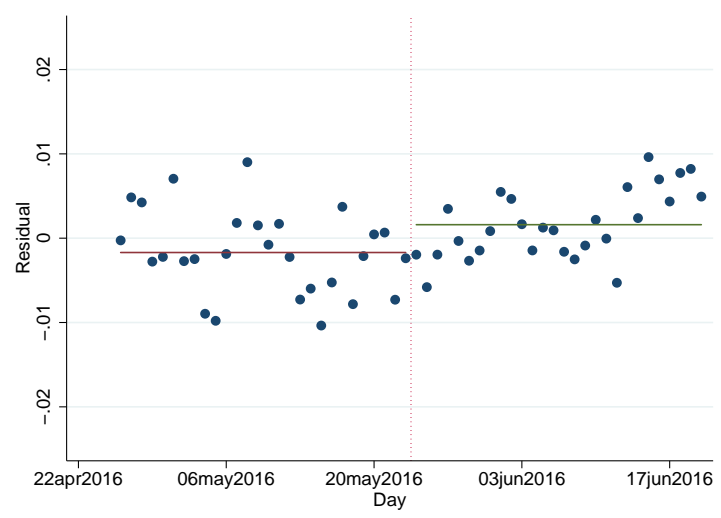

(b) Desktop: Residuals

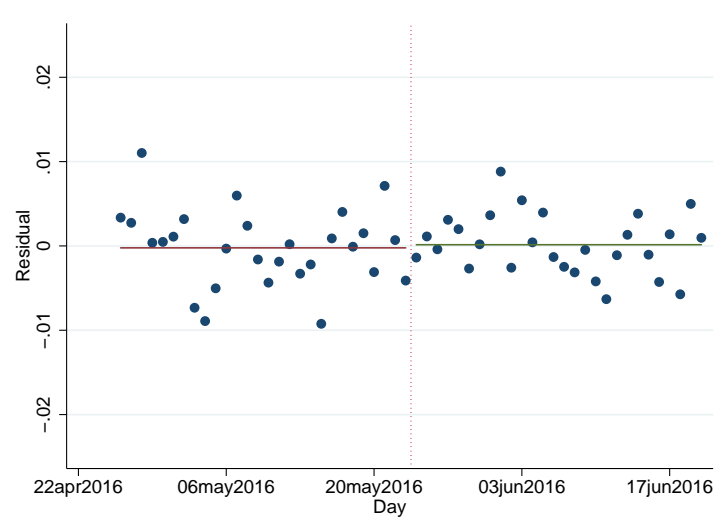

(d) Mobile: Residuals

Notes: Panels (a) and (c) depict scatterplots of the raw daily success rates for bargaining interactions grouped by the date of the first offer for desktop and mobile, respectively. Panels (b) and (d) depict residuals from a linear probability model regressing a dummy for successful bargaining on a large series of covariates (ln(ask price); category by condition fixed effects; day of week, precipitation, and holiday dummies and the temperature) for desktop and mobile, respectively. The vertical axes on both plots are scaled identically subject to a location shift.

half a percent. Two other features are apparent - first, there is substantial variation between days in the success rate of bargaining interactions, although this is rather smaller when we condition on the set of controls. Second, and more importantly, it appears that there is a positive drift in the residuals during the post period. In Section 5 we will offer a simple economic explanation for this finding: buyers and sellers are learning to communicate in the weeks following the policy change, leading to new behavior and better outcomes.

Consistent with models (3) and (4) of Table 3, we see no evidence of change in the likelihood that interactions are successful for buyers using the mobile platform.. 
We also see no positive drift in the residuals in the post period. This rationalizes our finding for the difference in differences estimator $\hat{\beta}_{d d}^{C}$ in models (5),(6),(7), and (8).

\subsubsection{Week-Specific Treatment Effects: Parallel Trends and Dynamics}

Next, we estimate a variant of (4) with week-specific effects over our eight-week sample:

$$
\mathbb{1}(\text { success })=\beta_{d d}^{0}+X \beta_{d d}^{1}+P \beta_{d d}^{2}+D \beta_{d d}^{3}+\sum_{t} P D \cdot \mathbb{1}(\text { week } t) \beta_{d d}^{C, t}+\varepsilon .
$$

We are interested in this model for two reasons. First, the divergence in the residualized scatterplots for desktop, Figure 5(b), and mobile, Figure 5(d), in the post-treatment period suggest that the effect of communication on bargaining is not immediate but delayed. Estimating week-specific effects will allow us to characterize these dynamics.

Second, following Autor (2003), estimating week-specific effects in the pre-period allows a partial test of the parallel trends assumption. If estimated week-specific effects in the pre-period are significant, this would violate Granger causality - that is, the effect would precede the cause, marking a failure of our identifying assumptions.

Results are depicted in Figure 6. We normalize the effect for week zero (just before the policy change) to zero. In the pre-period, our test of the joint significance of the coefficients fails to reject with a F-statistic of 0.11 (and an associated critical $p$ value of 0.9550). Therefore, we find neither a violation of the parallel trends assumption nor of Granger causality for our sample. Furthermore, the model permits us to interpret the positive drift in the post period from Figure 5(b) as a time-variant effect of communication. Despite almost instantaneous adoption, it took several weeks for the effects to be fully seen in the probability of bargaining success - this is perhaps not surprising, as conventions for communication may have taken some time to stabilize. ${ }^{19}$ We investigate this further with the content of the messages in Section 5.

\subsection{Additional Specifications and Outcomes}

Next, we summarize results from additional specifications, all of which are discussed in more detail in the Appendix.

We are interested in the effect of communication on other bargaining outcomes besides breakdown, especially in the hope that this might help us understand mecha-

\footnotetext{
${ }^{19}$ In Appendix 1 we estimate week-specific effects for the longer sample and show that the effect of communication on bargaining success stabilized and was consistent after week five.
} 
Figure 6: Week-Specific Effects

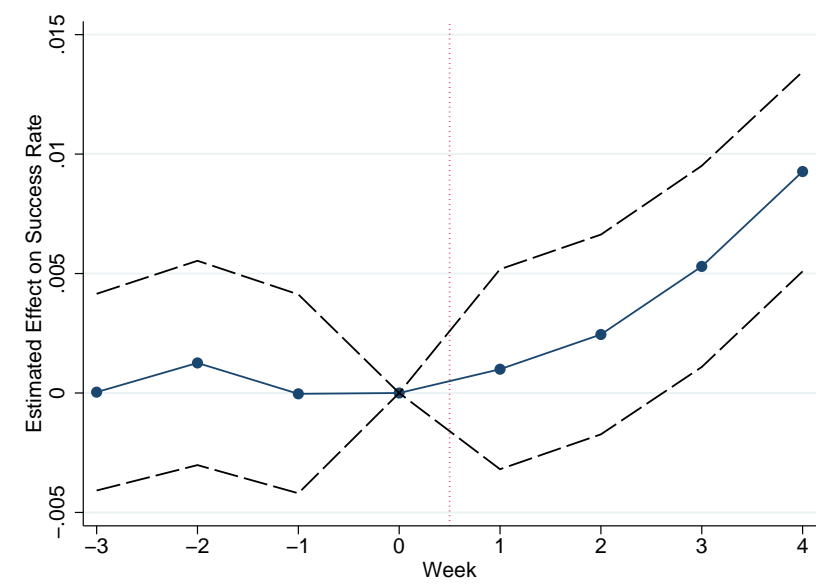

Notes: This figure depicts week-specific effects using the diff-in-diff approach with the main sample, 4 weeks before and 4 weeks after the policy change. The omitted coefficient (normalized to zero) is the week just prior to the change. Dashed lines represent a $95 \%$ confidence interval with heteroskedacticity-robust standard errors clustered by seller.

nisms and distributional consequences. With the caveat of limited power, we document our efforts in Appendix B. We find no statistically significant effects on the number of rounds or the first offer, but we do see a strong negative effect on the agreed-upon price. Examining this more closely, we condition on who made the final (accepted) offer in that sample, and find suggestive evidence that bargainers are successfully using messages to not only close the deal, but also to obtain more of the surplus.

In addition, in Appendix $\mathrm{C}$ we investigate heterogeneous treatment effects across asking price ranges and categories. Here our limited power is binding, however we find suggestive evidence that the effects are somewhat larger at lower price ranges (however, this is substantially flattened when we consider proportional effects, as success rates are much lower for higher asking price products).

Also, in Appendix D we consider robustness checks along two dimensions: first, the window used to construct the estimation sample and second, the inclusion of seller fixed effects. Both are supportive of the results of Table 3. We note that shortening the sample makes the effects no longer statistically significant, as one might intuit from Figure 6; that in extending it, the upward trend in Figure 6 stabilizes, and that seller fixed effects somewhat attenuate the result (from 0.0773 to 0.0561 ). 


\section{Evidence of Learning from Text Analysis}

In Section 4, we found a positive and significant relationship between bargaining efficiency and messaging. Moreover, by analyzing the week-specific effects of messaging, we observed that it took time for the full effect of communication to materialize. In this section, we explore the messages themselves in order to offer a plausible economic story for the strengthening relationship between messaging and bargaining success.

We compute the change in messaging content across weeks for both buyers and sellers, and are able to uncover some compelling patterns in messaging content. Namely, we find that messages sent by repeat sellers, or sellers who are sending multiple messages in our sample, are becoming more similar in content as the weeks pass. We additionally find convergent patterns in seller messages: specifically, the rate at which seller messages are changing is decreasing. These trends in seller messages are consistent with experience-based learning in which sellers adopt messaging strategies over time. We do not find similar results for buyers, where there are far fewer who are sending multiple messages in our sample.

\subsection{Messaging Data}

We have 248,722 messages of buyer and seller interactions for the ten-week period succeeding the introduction of messaging beginning on May 25, 2016. ${ }^{20}$ We process these messages through the following steps: First, we identify and keep only the messages sent in German in order to maintain a common corpus of words for our analysis; this makes up the vast majority (81.1 percent) of our dataset with the next most common language being English (which accounts for 6.4 percent of the messages). Second, the lower-cased messages are stripped of non-alphabetic characters, urls, extra spaces, and a list of common stop words - these are words such as "and" and "the" that provide little meaning in our messages. We then apply NLTK's German Snowball Stemmer (Bird et al. (2009)) to the tokens (ie. words) in each message so that they are transformed to their original stems. For instance, the word "angeboten" ("offered") is minimized to "angebot" ("offer"). This step is common practice in natural language processing and allows us to consider effectively synonymous words as the same word. ${ }^{21}$

\footnotetext{
${ }^{20}$ Our textual analysis starts two days after the change due to low take up on May 23-24, 2016.

${ }^{21}$ Please refer to Appendix Section E2 for a more detailed discussion of the construction of our messaging dataset, including a description of the list of stop words we remove from our dataset.
} 
Table 4: Buyer and Seller Messaging Characteristics Based on Experience

\begin{tabular}{lcccc}
\hline & Number of Messages & Unique Individuals & Average Message Length & Success Frequency \\
\hline Buyer & & & & \\
All Messages & 93576 & 76415 & 9.293 & 0.309 \\
One Message & 64648 & 64648 & 9.250 & 0.339 \\
Two - Four Messages & 25595 & 11271 & 9.379 & 0.244 \\
Five+ Messages & 3333 & 496 & 9.475 & 0.240 \\
Seller & & & & \\
All Messages & 116081 & 60076 & 8.513 & 0.228 \\
One Message & 40350 & 40350 & 8.218 & 0.243 \\
Two - Four Messages & 40541 & 16375 & 8.561 & 0.213 \\
Five+ Messages & 35190 & 3351 & 8.796 & 0.227 \\
\hline
\end{tabular}

Notes: In the first column messages are split based on whether the message's corresponding buyer or seller sent one, two to four, or five plus messages. Average message length refers to the average number of tokens in each message for that group. Success is defined by whether that message ends in a sale.

The final reduced dataset amounts to 209,658 messages split into 93,577 buyer messages and 116,081 seller messages. Table 4 provides descriptive statistics for buyer and seller messages split by experience level, which we define as the total count of messages sent by that seller or buyer over the ten-week period. Here we see that buyers tend to be "short-run" players, with only 496 buyers sending five or more messages. In contrast, individual sellers are more persistent in our dataset - there are 3,351 who are sending five or more messages.

Next, Table 5 depicts the ten most common tokens for buyers and sellers. Here, sellers messages appear to be slightly more negative in messaging content as "not" is the second most common word; additionally, "unfortunately" is the eighth most frequent token to appear in seller messages. For a more thorough description of the messages in our dataset, see Appendix Section E.

\subsection{Empirical Challenges and Methods}

Representing textual data constitutes a unique and increasingly common challenge in empirical research. In order to analyze seller and buyer messages, we must first construct a measure for the content of each message.

To do this, we split each message into a series of bigrams, a two-word pairing formed from consecutive words. For example, message $m$ as "this is my last offer" would be broken up into the parts: ["this is," "is my," "my last," and "last offer"]. Splitting the messages into bigrams, rather than single-word tokens, allows us to 
Table 5: Buyer and Seller Most Common Tokens

\begin{tabular}{cllcllc}
\hline Rank & Buyer Token & Translation & Frequency & Seller Token & Translation & Frequency \\
\hline 1 & Hallo & Hello & 0.031 & Nicht & Not & 0.032 \\
2 & Wurd & Would & 0.030 & Hallo & Hello & 0.024 \\
3 & Gruss & Greeting & 0.025 & Gruss & Greeting & 0.023 \\
4 & Versand & Shipping & 0.018 & Preis & Price & 0.021 \\
5 & Nicht & Not & 0.016 & Euro & Euro & 0.020 \\
6 & Euro & Euro & 0.015 & Versand & Shipping & 0.016 \\
7 & Mfg & Kind regards & 0.011 & Leid & Unfortunately & 0.015 \\
8 & Dank & Thanks & 0.011 & Dank & Thanks & 0.013 \\
9 & Kauf & Purchase & 0.010 & Schon & Beautiful & 0.012 \\
10 & Preis & Price & 0.010 & Mfg & Kind regards & 0.011 \\
\hline
\end{tabular}

Notes: This table reports the frequency of the ten most common tokens in our processed dataset for buyers and sellers. Tokens are translated to English for readability.

simplify each message while still incorporating some level of context in our textual analysis. An example of this are the words "screw" and "you," put together "screw you" has a much stronger meaning than the two words apart.

Next, we collapse our data into what is known as a "bag-of-words," or in our case, a "bag-of-bigrams," where each message is a row and each bigram a column. This exercise is frequently used in natural language processing (see Gentzkow et al. (2019a)); however, as analyzing textual data is still relatively new to economics, we will detail what this means below.

Our bag-of-bigrams is in the form of the matrix $\mathbf{C}_{i}$, where element $c_{i, m j}$ corresponds to the number of counts for phrase $j$ in message $m$ for group $i$, ie. some group of buyers or sellers. $\mathbf{C}_{i}$ is a high dimensional matrix. For instance, $\mathbf{C}_{s}$ for all seller messages in our dataset makes up a 116,081-by-287,241 matrix accounting for 116,081 seller messages and the 287,241 distinct bigrams that appear in these messages. Similarly, $\mathbf{C}_{b}$ for buyer messages forms a matrix with dimensions 93,577-by-331,904.

We are interested in changes in messaging content at the weekly level: Thus, we collapse $\mathbf{C}_{i}$ to $\mathbf{C}_{i}^{\prime}$. $\mathbf{C}_{i}^{\prime}$ is a ten-by- $X$ matrix with each row corresponding to a week in our ten-week sample and $X$ representing the number of distinct bigrams sent by group $i$. Element $c_{i, w j}^{\prime}$ then equates to the number of times phrase $j$ appears in the messages sent during week $w$ by group $i$.

Finally, we take vector $\mathbf{v}_{w}$ from row $w$ of $\mathbf{C}_{i}^{\prime}$ and compute the cosine distance between $\mathbf{v}_{w}$ and all rows in $\mathbf{C}_{i}^{\prime}$. The cosine distance between vector $\mathbf{v}_{w 1}$ and $\mathbf{v}_{w 2}$ is 
given by

$$
1-\frac{\mathbf{v}_{w 1} \cdot \mathbf{v}_{w 2}}{\left|\mathbf{v}_{w 1}\right|\left|\mathbf{v}_{w 2}\right|},
$$

where $\cdot$ represents the dot product and $\left|\mathbf{v}_{w}\right|$ is the $\ell^{2}$ norm.

The cosine distance measures one minus the cosine of the angle between $\mathbf{v}_{w 1}$ and $\mathbf{v}_{w 2}$ and is a standard method for computing text dissimilarity. The normalizing term in the denominator of (7) is desirable in our case as it scales the distance between the two vectors by each vector's length. This is essential in our context as the sum of bigram counts varies week from week due to changes in the take-up of messaging, holidays, etc. Finally, the cosine distance is our metric of choice as it supplies an intuitive measure of the distance between bigram counts across weeks. Since our vectors are by construction composed of nonnegative values, the cosine distance in this case will always be in the range $[0,1]$. Here, two weeks with orthogonal vectors will have a cosine distance of 1 , whereas the cosine distance will approach 0 as the two vectors get more similar in counts.

Finally, in order to clearly present the cosine distances across each pairing of weeks, we construct a ten-by-ten matrix of cosine distances with the $w_{1} w_{2}$ th element corresponding to the cosine distance between the vector of bigram counts in week $w_{1}$ and the vector of bigram counts in week $w_{2}$.

\subsection{Dynamics of Communication by Experience}

In Figure 7, we present our results through a heat map depicting the cosine distances between the bigram counts across weeks for buyers, Panel (a), and sellers, Panel (b). The colors indicate cosine distances in which the lighter boxes convey greater differences in messaging content, while the messages get more similar as the boxes get darker.

In Panel (a) of Figure 7, the cosine distances between buyer messages is stable across our ten-week period; we can see this as all the boxes in the heat map appear to be similar shades of blue. Table 4 offers a plausible explanation for this consistency in buyer messages across weeks: There are few buyers in our sample sending multiple messages. Specifically, only 3,333 messages are sent from buyers whose total message count is five or more. In contrast, 35,190 messages are sent by sellers with five or more messages. Due to the lack of repeat buyers, any changes in Panel (a) are presumably 
Figure 7: Cosine Distance of Buyer and Seller Messages by Week following the Introduction of Messaging

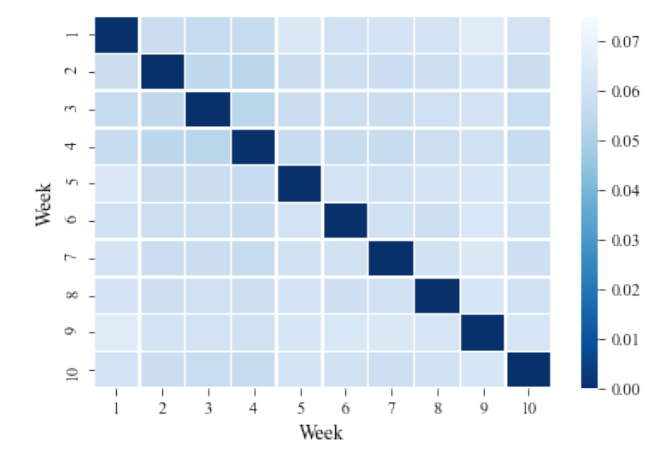

(a) Buyer

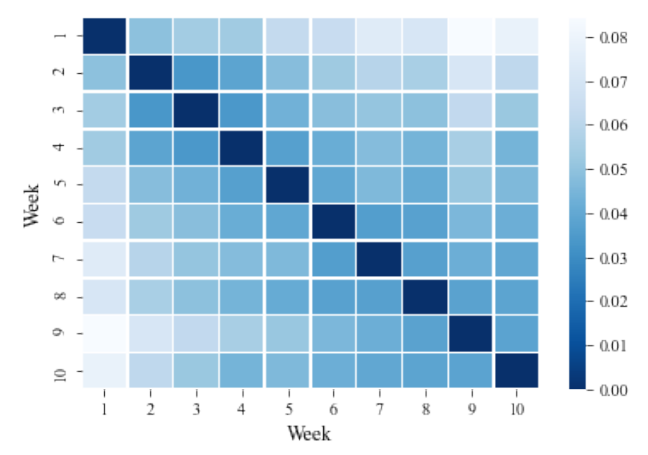

(b) Seller

Notes: This figure presents the cosine distance of the bigram counts in the messages between each of the ten weeks following May 25, 2016, for buyers, in Panel (a), and sellers, in Panel (b).

due to noise and week-effects. For instance, we observe differential usage of the word "urlaub" or "vacation" in our sample. Buyer messages include "vacation" 61 times during the week of July 20th, while they only mention "vacation" 21 times during the first week of our sample (May 25 - 31).

Panel (b) of Figure 7 portrays starkly different results; here, there are clearly changes in content across sellers messages from week to week as made evident due to the patterns of color occurring in seller messages. Still, it is challenging to discern exactly how seller messages are transforming. In order to amend this, there are two ways in which we can more intuitively decipher the patterns presented in the heat maps. First, we can more closely observe the bottom gradient of the heat maps, where we are comparing the differences in messaging content between week $w$ and week 10 . Second, we can plot the off-diagonals of the heat maps in order to see the rate of change in message content. The former will tell us whether the content of the text is changing systematically, where the latter will tell us whether it is convergent. That is, if the rate of change is decreasing, we take this as evidence of the convex pattern that is signature of models of learning and information: that our first data points teach us more than those that follow.

Figure 8 depicts a plot of the the cosine distances between week $w$ and week ten (the bottom gradient) for buyers and sellers. In this figure, we also depict the results 
for (nested) subsamples with different experience levels, where we define experience by the number of messages sent by that seller/buyer over our entire sample. Separating by experience level will allow us to isolate the sellers for whom we are more likely to observe patterns of learning. The scale of each plot is normalized to 1 in the last week; we do this because sampling variation, which is more salient as we restrict the sample size, biases the cosine distance measure upwards and makes levels uninterpretable. ${ }^{22}$ Note also that the scales of panels (a) and (b) are different.

Panel (a) depicts the differences in messages between week $w$ and week 10 for buyers. The line for "All" includes all buyers, and corresponds directly to the values in the bottom row of the heat map in panel (a) of Figure 7. For buyers with one, two, or three or more messages, the cosine distance does not appear to be changing. For buyers with four, five, and six or more messages, the cosine distance is decreasing over time, but this is obscured by sampling variation due to the small number of buyers in these sets.

In Panel (b), we again observe sharply different results for sellers. Here again, the line for "All" includes all sellers, and corresponds directly to the values in the bottom row of the heat map in panel (b) of Figure 7. For all samples, we see that as the weeks get closer to week 10, seller messages are increasingly more similar in content to the messages from this last week. Note also that the change is more pronounced among more experienced sellers. For instance, we see the sharpest trend for sellers that sent 6 or more messages, where there is a substantial difference in the cosine distance between the set of week 1 and 10 messages and the set of week 9 and 10 messages. These patterns suggest that as the weeks pass, sellers may be adopting new messaging strategies; moreover, it appears that repeat sellers are driving the changes in Figure 7.

So far, we have established that repeat sellers' messaging strategies are changing as they accumulate experience. We would like to ask whether, in addition, the changes are convergent, i.e. whether they represent a pattern that reflects learning. To do this, we plot the cosine distance across different periods of the same length to see whether the differences in message content are decreasing at a slower or faster rate over time. The objects we are depicting correspond to the off-diagonal elements of the heat map in Figure 7. The different off-diagonals represent differences over varying lengths of

\footnotetext{
${ }^{22}$ See Appendix Figure A-6 for the non-normalized version.
} 
Figure 8: The Bottom Gradient for Buyers and Sellers with Different Experience Levels

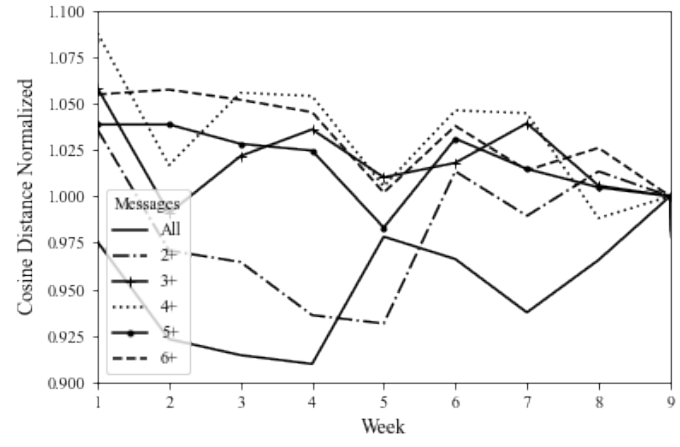

(a) Buyer

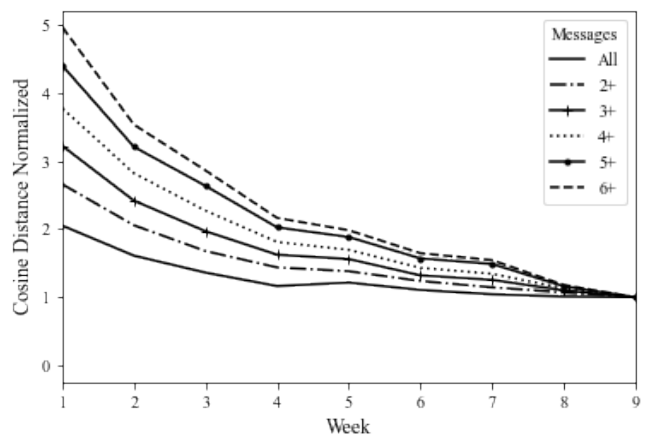

(b) Seller

Notes: This figure presents the cosine distance between the messages sent in weeks $\mathrm{x}$ and 10 for buyers, Panel (a), and sellers, Panel (b). The cosine distance is scaled by the distance between week 9 and week 10 messages. Each panel is cut by groups, where All includes our entire sample of buyers/sellers, $2+$ indicates our sample of messages sent by buyers/sellers who sent 2 or more messages, $3+$ from our sample of messages sent by buyers/sellers who sent 3 or more messages, and so on.

time; we depict them all because we are concerned that high-frequency differences may exaggerate the ratio of noise to signal.

Figure 9, plots the off-diagonals for all buyers, Panel (a), and sellers, Panel (b). In this plot, $\Delta x$ for week $w$ corresponds to the cosine distance in messages between week $w$ and week $w-x$. As suspected, Panel (c) portrays a noisy plot with no obvious patterns in buyer messages; on the other hand, there appears to be a downward trend in the $\Delta x$ 's in Panel (d). Thus, while seller messages are becoming more similar over time, they do so at a declining rate.

Figure 9 depicts the off-diagonals corresponding to the "All" groups of Figure 8, but from the latter we saw that repeat sellers are changing their messaging content more than transient ones. So, in Figure 10 we reproduces the same exercise for sellers who sent 5 or more messages in our ten-week period. As a reference point, the heat map for this group of sellers is depicted in Panel (a). Already, we see starker patterns in the change in message content across weeks. Panel (b) presents the off-diagonal plot for this group of sellers. Again, the patterns that previously emerged for our entire dataset of sellers become much more explicit when we restrict our analysis to repeat sellers. For instance, from $\Delta 5$ in Panel (b) we can see that sellers' messages between weeks 8 and 3 are more similar than in comparison to the messages for weeks 
Figure 9: Off-Diagonals for Buyers and Sellers

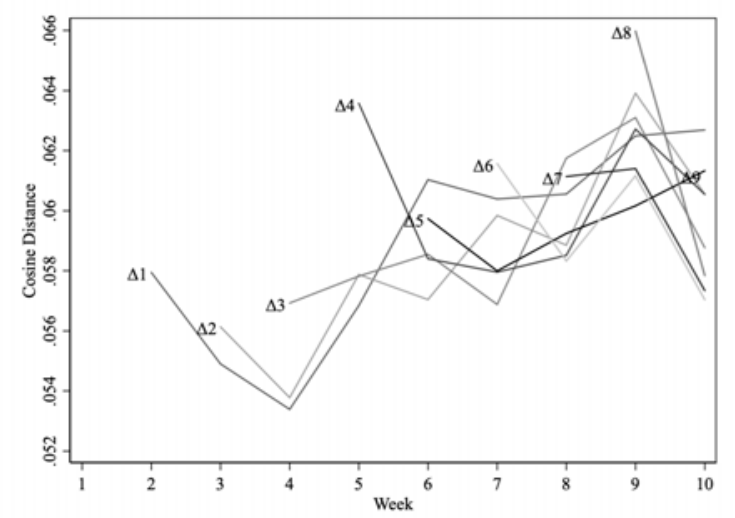

(a) Buyer

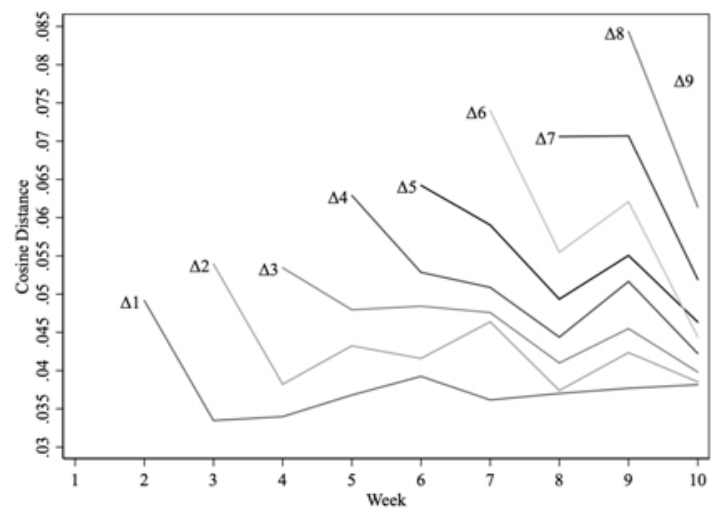

(b) Seller

Notes: This figure displays the change in cosine distance of bigram counts in the messages for different periods of time following May 25, 2016, separately for buyers, in Panel (a), and sellers, in Panel (b). $\Delta x$ for week $w$ indicates the cosine distance between week $w$ and week $w-x$.

7 and 2 and weeks 6 and 1. Or in other words, as repeat sellers learn to use similar messaging strategies over time, they are doing so at a declining rate as the weeks pass. This convergent path in which sellers are changing their messaging content faster in the beginning weeks following the messaging intervention, and then more slowly as time goes by, is consistent with experienced sellers learning how to use messages to facilitate transactions.

Most importantly, these results offer a simple explanation for the dynamics seen in Section 4.2.3, where we find a time-variant effect of communication on bargaining success that stabilizes following week five.

Further evidence is offered in Figure A-4 of the Appendix where we have included the heat maps and off-diagonal plots for sellers who sent two, three, and four or more messages. In addition, Figure A-5 in the Appendix presents the results for both sellers and buyers who appear only once in our dataset. Here, the effects presented above are completely attenuated when looking at this group of sellers, further providing evidence that these patterns of convergence are due to changes in messaging content by experienced sellers. 
Figure 10: Convergence Among Sellers with Five or More Messages

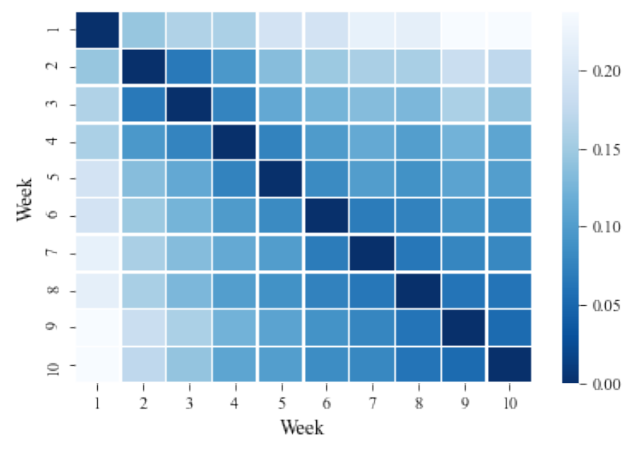

(a) $5+$ Messages

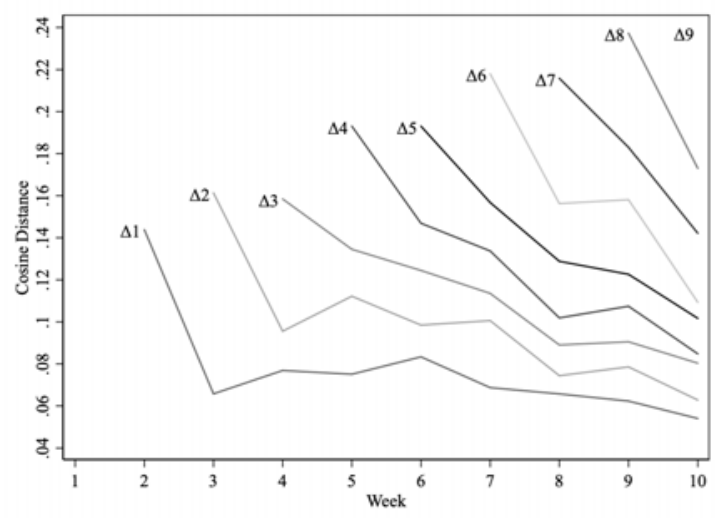

(b) $5+$ Messages

Notes: Panel (a) depicts the heat map representing the cosine distance of the bigram counts in the messages for each pairing of weeks following May 25, 2016 for sellers that sent five or more messages. Panel (b) plots the off-diagonals of the heat map from (a). $\Delta x$ for week $w$ indicates the cosine distance between week $w$ and week $w-x$.

\section{$6 \quad$ Message Experience Predicts Success}

In Section 4.2.3, we found a time-variant effect of communication on the success rate of bargaining; namely, it took several weeks for the full effect on the success rate to manifest. Similarly, the results from Section 5.3 indicate that seller messages are changing over time, and that they are doing so in a convergent pattern.

Given these findings, the natural next question is whether there exists a relationship between the change in messaging content and bargaining success. Here, we are motivated by the bottom gradient trends in Panel (b) of Figure 8. This figure shows that seller messages are becoming more similar as the weeks approach week 10 .

To explore whether these changes are associated with shifts in the seller success rate, we calculated the cosine similarity between each message and the aggregated set of bigram counts from the messages sent by sellers in week 10 . We regress message success, a binary variable representing whether that seller's message ended in a sale, onto this cosine similarity measure. ${ }^{23}$

\footnotetext{
${ }^{23}$ In this analysis we exclude a small set of sellers who send more than 20 messages. We do this because we believe that a) they are qualitatively different, professional sellers and b) they are overrepresented in message-level regressions. Overall, we are dropping 217 sellers that sent 21 or more messages; this is out of our original sample of 60, 076 sellers. In Appendix Section 4 we report variations, including using all sellers and the set of sellers that sent fewer than 11 messages.
} 
Table 6: The Relationship Between Message Success and Cosine Similarity

\begin{tabular}{lccc}
\hline \hline & $(1)$ & $(2)$ & $(3)$ \\
\hline $\operatorname{Sim}(m$, week 10) & $0.0661^{*}$ & $0.0559^{*}$ & 0.0490 \\
& $(0.0226)$ & $(0.0227)$ & $(0.0428)$ \\
& & & \\
Message Length & & $0.0013^{*}$ & 0.0003 \\
& & $(0.0002)$ & $(0.0005)$ \\
\hline $\mathrm{N}$ & 101931 & 101931 & 62217 \\
Controls & $\checkmark$ & $\checkmark$ & $\checkmark$ \\
Seller FE & & & $\checkmark$ \\
\hline \hline
\end{tabular}

Notes: This table presents our results on message success and a measure of message experience. Sim $(m$, week 10$)$ is the cosine similarity between a message and the set of week 10 messages excluding sellers who sent more than 21 messages. All models include our main set of controls: time trend; $\ln ($ ask price); category by condition fixed effects; day of week, precipitation, holiday dummies, and the temperature. Likewise, all models drop sellers sending more than 20 messages. Model (3) includes seller fixed effects. Robust standard errors are reported in parentheses and * denotes statistical significance at $\alpha=0.05$.

Table 6 presents our results. In all specifications we include the same set of controls as documented in Section 3.2. Finally, Models (2) and (3) also control for message length, as measured by the number of tokens in the processed message. Model (3) includes seller fixed effects.

In Model (1), we find a statistically significant effect that going from a completely orthogonal message to a message containing the set of week 10 messages is associated with an increase in the probability of success by 6.61 percentage points. In Model (2), we further find that message length has a positive, but economically small, relationship with the success rate. Finally, our result is no longer statistically significant, in Model (3), when including seller fixed effects. We have only 3,134 sellers sending more than five messages, but fewer than 21; as a result, we lose a considerable amount of power in our estimates when restricting attention to within-seller variation. Still, the relationship between our cosine similarity measures and message success remains positive.

Altogether, Table 6 points to a positive correlation between the probability of message success and the similarity between the message and the set of week 10 seller messages. Notably, the point estimates from this table are similar in magnitude to the point-estimates from Table 3, where we found that among our treatment group, interactions that involved messages were 7.73 percentage points more likely to end in success. 
A limitation of our approach is that we have not been able to address the direct mechanism in which messages contribute to higher rates of bargaining success. While we cannot provide causal evidence on this front, we implement a distributed multinomial model from Taddy (2015) in Appendix Section F. Here we consider the relationship between the bigrams included in seller messages and the message number sent by that seller, a measure of seller experience, which we have found to be related to message success. This analysis attempts to further understand how seller messaging content is changing, and through this descriptive exercise, we suggest some potential strategies that sellers may be implementing.

Table A-7 then presents the bigrams, both in English and the original German, that are the most and least predictive of seller experience, conditional on a set of controls. In addition, we use the bigram coefficients estimated from our model to compute message experience scores; here, a higher score indicates a message associated with higher levels of seller experience. Table A-8 then shows the messages with the highest experience scores, while Table A-9 includes the messages with the lowest scores.

Among the messages that are most correlated with experience, we see an emphasis on costs, especially those which may not be salient to buyers, such as the eBay commission. ${ }^{24}$ This is consistent with prior work highlighting the effectiveness of cost rationales originally raised by Kahneman et al. (1986), and re-emphasized in a bargaining setting by Lee and Ames (2017). The latter work contrasts cost rationales with disparagement rationales, showing the latter to be ineffective. With respect to this, our focus on seller messages obviates disparagement, however we do observe that, among those messages least predictive of experience, arguments about the quality of the product are common. We also see that where those most correlated with experience are restrained, polite, and precise, those less so tend to use more effusive language, which is reminiscent of the finding, by Jeong et al. (2019), that warm language may be counterproductive in negotiations.

\footnotetext{
${ }^{24}$ The price that the buyer pays is not received by the seller. Instead, the platform takes a "final value fee" in the range of $10 \%$. Buyers who have never been on the other side of the marketplace might easily be unaware of this fact.
} 


\section{Discussion}

In this paper we exploited a natural experiment in the availability of text messaging in bargaining to study the role of cheap-talk communication in avoiding bargaining breakdown. We found a statistically and economically significant effect: bargainers who used the messaging feature were on average eight percentage points more likely to transact. Against the sample average success rate of forty-four percent, this implies a fourteen percent reduction in the likelihood of bargaining breakdown.

We are unaware of any prior empirical work on communication in bargaining, however our results are consistent with a line of thought from the experimental and theoretical literature that suggests a role for behavioral considerations in bargaining. These papers have found that players communicate "too much" to be rationalized by rational models of cheap talk, and offer suggestive evidence that communication allows bargainers to outperform theoretical upper bounds to bargaining efficiency in the canonical, rational model with incomplete information. From the perspective of the literature, our results cast a positive light on efforts to test models that incorporate behavioral components to understand the role of communication (Miettinen, 2013; Dufwenberg et al., 2017).

From a market design perspective, our results suggest that communication has an important role to play in fostering transactions. However, this analysis has sidestepped a competing concern of platforms: that allowing communication may enable parties to take their transactions off the platform to avoid fees. Conspicuously, among the three largest online platforms that allow bargaining, Amazon both charges the highest transaction fee and does not facilitate communication between buyers and sellers. While we have no data on such off-platform transactions and cannot speak to their frequency, we do note that they would appear as bargaining failure in our dataset. Therefore, if communication is facilitating bargainers taking transactions offline, our results can be interpreted as net of any such effect, and in that sense a conservative estimate of the effect of communication on breakdown.

Our finding that communication plays an important role in bargaining raises at least as many questions as it answers, and we believe this is an important area for continued work. A promising direction that we have broached but not exhausted is to use developments in natural language processing and text analysis to study the content of what people say, above and beyond the fact that they say something. These 
questions have already been raised in experimental settings (see Lee and Ames (2017) for a recent contribution to, and summary of, this literature in social psychology). The availability of data from online bargaining marketplaces is an opportunity to see them in the field and directly link them to economic outcomes. Understanding how to improve bargaining outcomes is among the most central questions in economics, and also among the questions on which we have made the least progress, in part due to a lack of empirical work using data from real market interactions. Our paper tries to fill some of that gap, and our results highlight the importance of communication in bargaining. As Farrell and Gibbons (1989) write, "the economic importance of costless, nonverifiable, informal communication is much greater than its role in the literature suggests." Our result documents empirically that this remains true today. 


\section{References}

Angrist, Joshua D., Guido W. Imbens, and Donald B. Rubin, "Identification of Causal Effects Using Instrumental Variables," Journal of the American Statistical Association, 1996, 91 (434), 444-455.

Autor, David, "Outsourcing at Will: The Contribution of Unjust Dismissal Doctrine to the Growth of Employment Outsourcing," Journal of Labor Economics, 2003, 21 (1), 1-42.

Awaya, Yu and Vijay Krishna, "On Communication and Collusion," American Economic Review, 2015, 106 (2), 285-315.

Ayres, Ian and Barry Nalebuff, "Common Knowledge as a Barrier to Negotiation," UCLA Law Review, 1997, 44 (6), 1631-1660.

Backus, Matthew, Tom Blake, and Steven Tadelis, "On the Empirical Content of Cheap-Talk Signaling: An Application to Bargaining," The Journal of Political Economy, 2019, 127 (4), 1599-1628.

_ , _, Bradley Larsen, and Steven Tadelis, "Sequential Bargaining in the Field: Evidence from Millions of Online Bargaining Interactions," Quarterly Journal of Economics, 2020, 135 (3), $1319-1361$.

Belkin, Liuba Y, Terri R Kurtzberg, and Charles E Naquin, "Signaling Dominance in Online Negotiations: The Role of Affective Tone," Negotiation and Conflict Management Research, 2013, $6(4), 285-304$.

Bird, Steve, Edward Loper, and Ewan Klein, in "Natural Language Processing with Python," O'Reilly Media Inc., 2009.

Blume, Andreas and Andreas Ortmann, "The Effects of Costless Pre-Play Communication: Experimental Evidence from Games with Pareto-Ranked Equilibria," Journal of Economic Theory, 2007, 132 (1), 274-290.

Bolton, Gary E., Kalyan Chatterjee, and Kathleen L. McGinn, "How Communication Links Influence Coalition Bargaining: A Laboratory Investigation," Management Science, 2003, 49 (5), $583-598$.

Brown, Jennifer Gerarda and Ian Ayres, "Economic Rationales for Mediation," Virginia Law Review, 1994, 80 (2), 323-402.

Cabral, Luis and József Sákovics, "Must Sell," Journal of Econoomics and Management Strategy, $1995,4(1), 55-68$.

Cai, Hongbin and Joseph Tao-Yi Wang, "Overcommunication in Strategic Information Transmission Games," Games and Economic Behavior, 2006, 56, 7-36.

Card, David and Gordon Dahl, "Bargaining and the Role of Expert Agents: An Empirical Study of Final-Offer Arbitration," The Review of Economics and Statistics, 2012, 94 (1), 116-132.

Charness, Gary, Communication in Bargaining Experiments, Vol. Oxford Handbook of Economic Conflict Resolution, Oxford University Press,

— and Martin Dufwenberg, "Promises and Partnership," Econometrica, 2006, 74 (6), 1579-1601. 
_ and _, "Participation," American Economic Review, 2011, 101, 1211-1237.

Clark, Robert and Jean-François Houde, "The Effect of Explicit Communication on Pricing: Evidence from the Collapse of a Gasoline Cartel," The Journal of Industrial Economics, 2014, 62 (2), 191-228.

Coffman, Lucas and Paul Niehaus, "Pathways of Persuasion," Games and Economic Behavior, 2020, 124, 239-253.

Cooper, David J. and Kai-Uwe Kühn, "Commuication, Renegotiation, and the Scope for Collusion," American Economic Journal: Microeconomics, 2014, 6 (2), 247-278.

Cooper, Russel, Douglas V. DeJong, Robert Forsythe, and Thomas W. Ross, "Communication in Coordination Games," Quarterly Journal of Economics, 1992, 107 (2), 739-771.

Crawford, Vincent P., "A Theory of Disagreemnt in Bargaining," Econometrica, 1982, 50 (3), 607-637.

_ , "Explicit Communication and Bargaining Outcomes," American Economic Review, 1990, 80 (2), $213-219$.

- and Joel Sobel, "Strategic Information Transmission," Econometrica, 1982, 50 (6), 1431-1451.

_ , Miguel A. Costa-Gomes, and Nagore Iriberri, "Structural Models of Nonequilibrium Strategic Thinking: Theory, Evidence, and Applications," Journal of Economic Literature, 2013, $51(1), 5-62$.

Doraszelski, Ulrich, Gregory Lewis, and Ariel Pakes, "Just Starting Out: Learning and Price Competition in a New Market," 2017. accepted, American Economic Review.

Dufwenberg, Martin, Maroš Servátka, and Radovan Vadovič, "Honesty and Informal Agreements," Games and Economic Behavior, 2017, 102, 269-285.

Ellingsen, Tore and Robert Östling, "When Does Communication Improve Coordination?," American Economic Review, 2010, 100, 1695-1724.

Ert, Eyal, Stephanie Creary, and Max H. Bazerman, "Cynicism in Negotiation: When Communication Increases Buyers' Skepticism," Judgement and Decision Making, 2014, 9 (3), 191-198.

Farrell, Joseph and Robert Gibbons, "Cheap Talk Can Matter in Bargaining," Journal of Economic Theory, 1989, 48 (1), 221-237.

Fey, Mark and Kristopher W. Ramsay, "When is Shuttle Diplomacy Worth the Commute? Information Sharing through Mediation," World Politics, 2010, 62 (4), 529-560.

Gentzkow, Matthew, Bryan Kelly, and Matt Taddy, "Text as Data," Journal of Economic Literature, 2019, 57 (3), 535-574.

_ , Jesse M Shapiro, and Matt Taddy, "Measuring Group Differences in High-dimensional Choices: Method and Application to Congressional Speech," Econometrica, 2019, 87 (4), 13071340 .

Gibson, Ranja, Carmen Tanner, and Alexander Wagner, "Preferences for Truthfulness: Heterogeneity Among and Within Individuals," American Economic Review, 2013, 103 (1), $532-548$. 
Gizatulina, Alia and Olga Gorelkina, "Selling 'Money' on eBay: A Field Study of Surplus Division," 2017. Working Paper.

Gneezy, Uri, "Deception: The Role of Consequences," The American Economic Review, 2005, 95 (1), 384-394.

Goltsman, Maria, Johannes Hörner, Gregory Pavlov, and Francesco Squintani, "Mediation, Arbitration, and Negotiation," Journal of Economic Theory, 2009, 144 (4), 1397-1420.

Harrington, Joseph E. and Lixin Ye, "Collusion through Coordination of Announcements," The Journal of Industrial Economics, 2019, 67 (2), 209-241.

Hine, Michael J, Steven A Murphy, Michael Weber, and Gregory Kersten, "The Role of Emotion and Language in Dyadic E-Negotiations," Group Decision and Negotiation, 2009, 18 (3), 193-211.

Hörner, Johannes, Massimo Morelli, and Francesco Squintani, "Mediation and Peace," Review of Economic Studies, 2015, 82 (4), 1483-1501.

Jeong, Martha, Julia Minson, Michael Yeomans, and Francesca Gino, "Communicating with Warmth in Distributive Negotiations is Surprisingly Counterproductive," Management Science, 2019,65 (12), 5813-5837.

Kahneman, Daniel, Jack L. Knetsch, and Richard Thaler, "Fairness as a Constraint on Profit Seeking: Entitlemenets in the Market," American Economic Review, 1986, 76 (4), 728-741.

Kopelman, Shirli, Ashleigh Shelby Rosette, and Leigh Thompson, "The Three Faces of Eve: Strategic Displays of Positive, Negative, and Neutral Emotions in Negotiations," Organizational Behavior and Human Decision Processes, 2006, 99 (1), 81-101.

Lee, Alice J. and Daniel R. Ames, "II Can't Pay More" Versus "It's not Worth More": Divergent Effects of Constraint and Disparagement Rationales in Negotiations," Organizational Behavior and Human Decision Processes, 2017, 141, 16-28.

Loertscher, Simon and Leslie M. Marx, "Countervailing Power, Integration, and Investment under Incomplete Information," 2020. Working Paper.

McGinn, Kathleen L., Katherine L. Milkman, and Markus Nöth, "Walking the Talk in Multiparty Negotiation: An Experimental Investigation," Journal of Economic Psychology, 2012, 33 (1), 278-291.

_, Leigh Thompson, and Max H. Bazerman, "Dyadic Processes of Disclosure and Reciprocity in Bargaining with Communication," Journal of Behavioral Decision Making, 2003, 16, 17-34.

Menzio, Guido, "A Theory of Partially Directed Search," Journal of Political Economy, 2007, 115 (5), 748-769.

Miettinen, Topi, "Promises and Conventions - An Approach to Pre-Play Agreements," Games and Economic Behavior, 2013, 80, 68-84.

Myerson, Roger B and Mark A Satterthwaite, "Efficient mechanisms for bilateral trading," Journal of economic theory, 1983, 29 (2), 265-281.

Oberholzer-Gee, Felix and Julie Wulf, "Alibaba's TaoBao," Technical Report 9-709-456, Harvard Business School 2009. 
Radner, Roy and Andrew Schotter, "The Sealed-Bid Mehanism: An Experimental Study," Journal of Economic Theory, 1989, 48 (1), 179-220.

Rubinstein, Ariel, "Perfect Equilibrium in a Bargaining Model," Econometrica, 1982, 50 (1), 97-110.

Taddy, Matt, "Distributed Multinomial Regression," The Annals of Applied Statistics, 2015, 9 (3), 1394-1414.

Valley, Kathleen, Leigh Thompson, Robert Gibbons, and Max Bazerman, "How Communication Improves Efficiency in Bargaining Games," Games and Economic Behavior, 2002, 38 (1), $127-155$. 


\section{Appendices}

\section{A A Straw Man: OLS Estimates}

In the absence of a natural experiment, one might have been tempted to analyze the effect of communication by regressing a dummy for success on a dummy for the presence of a message. This will be misleading if bargainers are more likely to send messages when an interaction is, for reasons unobservable in our set of controls, less likely to succeed. In Table A-1 we present OLS estimates for such an analysis in a linear probability model approach.

Note that for these results we construct the message indicator a bit differently. $\mathbb{1}$ (Message $^{*}$ ) is actually $\mathbb{1}$ (complier), the product of three dummy variables: one for whether any message was sent, one for whether the first offer in the interaction was made after May 23, 2016 (to rule out misclassified messages), and one for whether the buyer is a desktop user (to rule out cases where a message was sent by the seller but the buyer could not read it because they were on the mobile app). In models (1) through (4) we progressively add additional controls. The coefficient on $\mathbb{1}$ (Message*) responds most significantly at the inclusion of $\ln$ (Asking Price), which is intuitive because messages are more common when bargaining over more expensive goods, recalling Table 2. However, the coefficient stabilizes at a relatively slight 1.5 percentage points, which is substantially lower than our estimated treatment-effect-on-the-treated of approximately 8 . We take this to mean that the endogenous decision of whether to send a message is strongly negatively correlated with the error term in the OLS regressions. That is, bargainers are more likely to use messages when the chances of success are slight for reasons unobservable to the econometrician-evidence for this already appears in the difference between models (1) and (2), where the inclusion of the asking price removes some of the negative bias. Recall from Table 2 that messages are more frequently sent when the asking price is greater, which is also where the likelihood of breakdown is greater. 
Table A-1: OLS Estimates

\begin{tabular}{|c|c|c|c|c|c|c|}
\hline & (1) & $(2)$ & $(3)$ & (4) & $(5)$ & (6) \\
\hline $\mathbb{1}$ (Message) & $\begin{array}{l}-0.0076^{*} \\
(0.0028)\end{array}$ & $\begin{array}{c}0.0208^{*} \\
(0.0027)\end{array}$ & $\begin{array}{l}0.0152^{*} \\
(0.0026)\end{array}$ & $\begin{array}{c}0.0151^{*} \\
(0.0026)\end{array}$ & & \\
\hline $\ln$ (Ask Price) & & $\begin{array}{c}-0.0827^{*} \\
(0.0013)\end{array}$ & $\begin{array}{c}-0.0840^{*} \\
(0.0013)\end{array}$ & $\begin{array}{c}-0.0840^{*} \\
(0.0013)\end{array}$ & $\begin{array}{c}-0.0840^{*} \\
(0.0013)\end{array}$ & $\begin{array}{c}-0.0840^{*} \\
(0.0013)\end{array}$ \\
\hline Time Trend & & $\begin{array}{c}0.0000 \\
(0.0000)\end{array}$ & $\begin{array}{c}0.0001 \\
(0.0000)\end{array}$ & $\begin{array}{c}0.0000 \\
(0.0000)\end{array}$ & $\begin{array}{c}0.0000 \\
(0.0000)\end{array}$ & \\
\hline $\mathbb{1}$ (Monday) & & & & $\begin{array}{c}0.0115^{*} \\
(0.0011)\end{array}$ & $\begin{array}{l}0.0115^{*} \\
(0.0011)\end{array}$ & $\begin{array}{c}0.0114^{*} \\
(0.0011)\end{array}$ \\
\hline $\mathbb{1}$ (Tuesday) & & & & $\begin{array}{c}0.0073^{*} \\
(0.0011)\end{array}$ & $\begin{array}{c}0.0074^{*} \\
(0.0011)\end{array}$ & $\begin{array}{c}0.0069^{*} \\
(0.0011)\end{array}$ \\
\hline $\mathbb{1}$ (Wednesday) & & & & $\begin{array}{c}0.0046^{*} \\
(0.0012)\end{array}$ & $\begin{array}{c}0.0046^{*} \\
(0.0012)\end{array}$ & $\begin{array}{c}0.0043^{*} \\
(0.0012)\end{array}$ \\
\hline $\mathbb{1}$ (Thursday) & & & & $\begin{array}{c}0.0022^{*} \\
(0.0011)\end{array}$ & $\begin{array}{c}0.0023^{*} \\
(0.0011)\end{array}$ & $\begin{array}{c}0.0022^{*} \\
(0.0011)\end{array}$ \\
\hline $\mathbb{1}$ (Friday) & & & & $\begin{array}{c}-0.0087^{*} \\
(0.0013)\end{array}$ & $\begin{array}{c}-0.0086^{*} \\
(0.0013)\end{array}$ & $\begin{array}{c}-0.0088^{*} \\
(0.0013)\end{array}$ \\
\hline $\mathbb{1}$ (Saturday) & & & & $\begin{array}{c}-0.0106^{*} \\
(0.0012)\end{array}$ & $\begin{array}{c}-0.0106^{*} \\
(0.0012)\end{array}$ & $\begin{array}{c}-0.0108^{*} \\
(0.0011)\end{array}$ \\
\hline $\mathbb{1}$ (Precipitation) & & & & $\begin{array}{c}-0.0014^{*} \\
(0.0007)\end{array}$ & $\begin{array}{c}-0.0014^{*} \\
(0.0007)\end{array}$ & $\begin{array}{c}-0.0008 \\
(0.0007)\end{array}$ \\
\hline $\mathbb{1}$ (Holiday) & & & & $\begin{array}{c}-0.0072^{*} \\
(0.0011)\end{array}$ & $\begin{array}{c}-0.0072^{*} \\
(0.0011)\end{array}$ & $\begin{array}{c}-0.0078^{*} \\
(0.0011)\end{array}$ \\
\hline Temperature & & & & $\begin{array}{c}0.0006^{*} \\
(0.0001)\end{array}$ & $\begin{array}{l}0.0006^{*} \\
(0.0001)\end{array}$ & $\begin{array}{c}0.0006^{*} \\
(0.0001)\end{array}$ \\
\hline $\begin{array}{l}\text { Category by Condition FE } \\
\mathrm{N}\end{array}$ & 3294362 & 3294362 & $\begin{array}{c}\checkmark \\
3294362\end{array}$ & $\begin{array}{c}\checkmark \\
3294362\end{array}$ & $\begin{array}{c}\checkmark \\
3294362\end{array}$ & $\begin{array}{c}\checkmark \\
3294362\end{array}$ \\
\hline
\end{tabular}

Notes: This table reports OLS coefficients from a linear probability model in which each observation is a bargaining interaction and the dependent variable is a dummy for whether negotiations ended in a transaction. $\mathbb{1}$ (Sunday) is excluded. Heteroskedacticity-robust standard errors, clustered by seller, are reported in parentheses, and ${ }^{*}$ denotes statistical significance at $\alpha=0.05$.

\section{B Alternative Outcomes}

The bulk of our analysis has taken a dummy for bargaining success as the dependent variable. We might also be interested to know how other bargaining outcomes change with the introduction of communication. For instance, do buyers negotiate better deals? Is bargaining prolonged? 
Our results for these questions are presented in Table A-2. Models (1) and (2) consider dependent variables for which we can use the entire sample: respectively, the number of offers in the bargaining interaction and the log of the first buyer offer. We find no statistically significant effect on either of these outcomes. In model (3) where we condition on bargaining success and measure the effect on negotiated prices. We find a strong negative effect. Note for models (2) and (3) that the controls include the sellers' asking price, so we can interpret this effect as a discount. One interpretation is that sellers have raised their asking prices, but we find such general equilibrium effects unlikely because of the low take-up rates of the messaging feature; also, we see no compositional changes in the prices bargained in the pre- and post periods. This leaves two additional hypotheses: first, that transactions that are new - that is, would not have happened but for messaging - are on average for lower-priced products than those that are not. This is consistent with the finding of Valley et al. (2002), as the new transactions are on the frontier where buyer and seller valuations are close, as well as our failure to find an effect on the buyer's initial offer. An alternative interpretation is that the composition of goods has not changed, but buyers are taking more of the surplus.

Next, in models (4), (5), and (6) we dive further into the question of the division of surplus. Here, we construct subsamples defined by the endogenous bargaining sequence. Model (4) uses the asking price for the subsample where the buyer's initial offer is accepted (recall that buyers always make the first offer). Model (5) takes the subsample in which the buyers initial offer was countered, and the seller's counter-offer was accepted. Finally, model (6) takes the subsample in which the buyer's initial offer was countered, then the buyer countered the seller's counter, and the seller accepted that counter-offer. In model (4) do we find an almost-significant effect. Moreover, the sign changes between the models are consistent with the hypothesis that bargainers are using messages to their own advantage. Note that the sample size shrinks fast when conditioning on these small subsets, so it is unsurprising that we lack the power to identify a significant effect. 


\section{Heterogeneous Effects}

\section{Effects by Price Range}

Next, we present estimates of $\beta_{i v}^{C}$ across different price categories in Table A-3. Our estimates range from 8.98 to 10.44 percentage points for interactions where the asking price is below $\$ 150$, and they are substantively smaller - statistically insignificant with point estimates ranging from 2.41 to 3.51 percentage points above $\$ 150$.

While it seems as if there is a substantially larger effect of communication for interactions that involve listings with lower asking prices, we note that this relationship flattens out when we consider the baseline success rates. Interactions in the lowestprice group (asking price less than \$50) are successful 52.94 percent of the time, while listings in highest-price group (asking prices above \$250) are successful 25.54 percent of the time. So the proportional effect is rather more similar - and not statistically distinguishable - and therefore we hesitate to draw conclusions.

\section{Variation Across Categories}

We next turn to category-specific estimates of $\beta_{i v}^{C}$. However, we note two words of caution: first, because the effects we are estimating are so small—from Table 3, on the order of half a percent - splitting our sample quickly erodes power. In that spirit, the standard errors should be interpreted with caution because a table with many estimates implicitly suffers a multiple comparison problem. Similarly, the ordinal relationships of the point estimates should be interpreted with substantial caution.

Second, we remind the reader that selection into the Best Offer mechanism is endogenous. The composition of, for instance, CDs and DVDs conditional on enabling Best Offer may be very different than CDs and DVDs more generally. While we may think of the latter as being rather standardized, the former may be more likely to include box sets and out-of-print collectors editions.

Estimates are presented in Figure A-1. The dependent variable remains a dummy for whether the bargaining ended in a transaction. Standard errors are not adjusted for the multiple comparison problem. While we find intuition in some of the findings, e.g. the large effect in Collectibles, others remain a puzzle, e.g. the large effect in 
Figure A-1: Category-Specific Effects

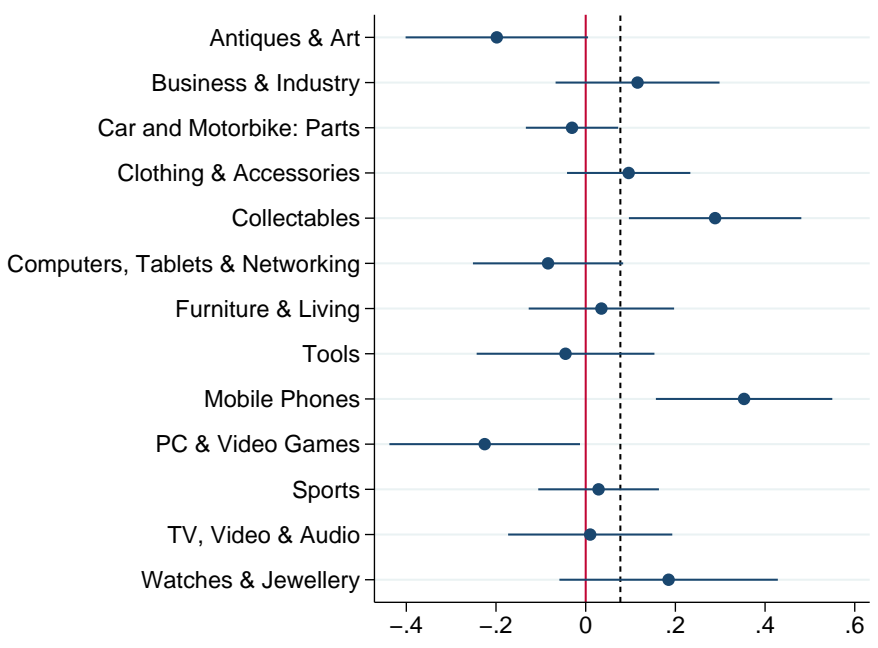

Notes: This figure presents category-specific estimates for all categories in our main sample with at least one hundred thousand interactions. The dependent variable is a dummy for whether the bargaining interaction ended in a transaction. All parameters of the model are estimated independently for each coefficient estimate. The solid vertical line is at zero, while the dashed vertical line is at our point estimate from Table 3 of 0.0773 for comparison.

Mobile Phones or the negative one in Antiques and Arts. For the reasons above, we do not put much stock in these comparisons, ordinal or absolute.

\section{Robustness}

\section{Sample Window}

As a simple robustness test, we check the sensitivity of our estimates to the sample window. The main sample window is four weeks before and four weeks after the change on May 23, 2016, depicted graphically in Figure 3. We also consider two, three, five, and six weeks in either direction, as well as the full dataset, seven weeks before and ten weeks after.

Table A-4 presents estimates varying the sample window. Consistent with the finding that the effect of introducing communication is not immediate, results are weaker for the shorter windows. This also reflects a loss of power as we lose observations. Extending the window for a longer time horizon, the estimates stabilize, however this may reflect other changes on the website. Consistent this, we also re-create Figure 6 for the full sample, estimating week-specific effects six weeks before and ten weeks 
after the policy change. Estimates are presented in Figure A-2. Here it appears that the treatment effect of communication stabilizes after five weeks.

Figure A-2: Week-Specific Effects-Extended Sample

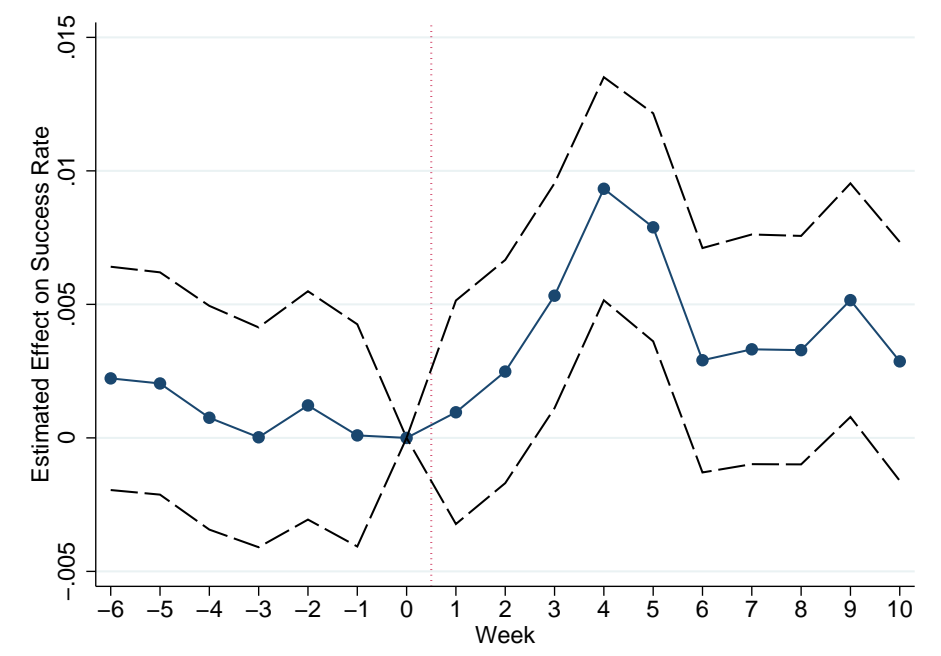

Notes: This figure depicts week-specific effects using the differences-in-differences approach with the extended sample which uses seven weeks before the change and ten after. The omitted coefficient (normalized to zero) is the week just prior to the change.

\section{$2 \quad$ Seller Fixed Effects}

Next, we consider replicating the estimates from Table 3 with seller fixed effects. This is meant to address a number of concerns. Most importantly, the category fixed effects that we include in our main specification are rather coarse, and so seller-level fixed effects might do a better job of controlling for product unobservables. In particular, we are concerned that the composition of listings on which interactions are occurring is different in unobservable ways for the treated group and the untreated group, which might lead us to find spurious effects.

Estimates are presented in Table A-5. We have limited ourselves to replicating only the models with the full set of controls. We see a slight attenuation of the estimates, but the $\hat{\beta}_{d d}^{C}$ and $\hat{\beta}_{i v}^{C}$ remain statistically significant and statistically indistinguishable from the estimates of Table 3. 


\section{E Text Analysis Details}

\section{Message Examples}

Table A-6 shows a curated set of examples messages sent with offers in our data. Messages range from the simple declaration of an offer to signals of willingness-to-pay or accept (e.g. "I do not go down") ${ }^{25}$ Some messages are meant to entice better offers, such as offering bulk discounts. Some messages clarify aspects of the item (like missing a hard drive). Still others seem like endearment and politeness, perhaps an attempt to foster or appeal to other-regarding preferences. Therefore, messages seem to serve a multitude of functions: cheap talk, signaling about buyer and seller characteristics, resolving informational uncertainties about the product, endearment, and more.

\section{Data Construction}

The text analysis of Section 5 uses the dataset of 248,722 messages sent in the ten weeks following May 25, 2016. This reflects some preliminary cleaning: messages consisting only of numbers or spaces are excluded. Also, messages such as "please enter your message here" (in a variety of languages), which we believe to be an artifact of third-party software for sellers to create listings and upload them via the API, have been manually detected and excluded.

Most of the analysis is conducted on the "processed" messaging dataset. The processing of the messaging takes place in four steps.

1. First, we use a Python implementation of Google's language detection algorithm to classify messages by language. After this, we keep only the messages that are detected to be in German.

2. Second, we remove all numbers, symbols, and extra spaces from each message.

3. Third, we remove stop words. This list of stop words comes from NLTK's set of German stop words. We remove "nicht" ("not") from this list as this token appears to be important in the context of bargaining.

4. Next, we stem the messages. To do this we use the NLTK's German Snowball Stemmer.

25 "MFG" is a common acronym translating to "with regards." 


\section{Heat Maps and their Corresponding Figures}

Figure A-3 shows our heat map results and off-diagonal plots for different cuts of buyers based on the number of messages they sent throughout the ten week period following the introduction of messaging on eBay Germany Best Offer. As expected, these figures are filled with noise and present no obvious patterns. Figure A-4 depicts the same figures, but for sellers. Here, we find that our results strengthen as we restrict attention to experienced sellers. As a robustness check, Figure A-5 presents the heat map figures and off-diagonal plots for buyers and sellers who only sent one message during this time period. We find that sellers that send only one message have no patterns in messaging content, which further suggests that seller learning is driving our results among experienced sellers.

Figure A-6 includes the bottom gradient results for buyers and sellers without being scaled by the cosine distance between week 9 and week 10 messages. As seen in Panel (a), the cosine distance for buyer messages is close to being orthogonal (near one) for the group of buyers that sent six or more and five or more messages. One reason we are getting this result is because we have few buyers who've sent multiple messages, for instance, only 496 buyers sent five or more messages. This highlights one weakness of our cosine distance measure, namely that it's sensitive to the number of messages in each sample.

As a robustness check, Figure A-7 then includes the number of messages by group for buyers and sellers across weeks. We also include these figures scaled by the number of messages in week 10. In this figure, there is some noise in the number of messages by week, however, we don't see a significant rise in the number of messages sent by the set of sellers with multiple messages in later weeks - such a rise would cause concern for our main results in Section 5.3.

\section{F An Exploration into Seller Messages}

In Section 4, we presented results that suggest that sellers are learning across our ten-week sample period; furthermore, we found that this result is driven by experienced sellers. In this section, we implement a distributed multinomial regression model (DMR) from Taddy (2015) that explores the relationship between seller experience and the bigrams sent by sellers in our messaging dataset. 


\section{Data Reduction}

For this analysis, we are using the same dataset as the one discussed in Section 5.1. Similar to Section 5.2, we construct a matrix $\mathbf{C}_{s}$ consisting of seller bigram counts; recall that element $c_{s, m j}$ of $\mathbf{C}_{s}$ corresponds to the number of counts for bigram $j$ in message $m$. Now, in order to lower the computational costs of running a regression model, we went through of series of cleaning steps. These steps were aimed at reducing some of the high dimensionality of our messaging dataset without loss of significant information - as mentioned, we have more than 280,000 bigrams in our original sample of seller messages.

The processing steps are as follows: 1) we remove bigrams that contain less than 5 characters, 2) we remove bigrams where one of the tokens in the bigram contain only 1 character, 3) we drop all sellers that sent more than 21 messages, 4) we remove all bigrams that are used less than 10 times across seller messages, 5) we drop bigrams that are said by only one seller, and 6) we remove the empty rows that the previous two steps created in matrix $\mathbf{C}_{s}$.

For step 3, we drop sellers that are sending more than 21 messages as we expect that these sellers might be very different than sellers sending between 1 and 20 messages; for instance, these serial sellers are probably more likely to be active on different sites and, as a result, they might already have had experience sending messages to buyers prior to the introduction of messaging on eBay's Germany Best Offer platform. Second, as we are concerned about how sellers are changing messaging content from one message to another, it makes sense for us to set bounds on the message number. Dropping these sellers from our sample only removes 217 sellers out of our original 60,076 . In total, these steps reduce the dimension of matrix $\mathbf{C}_{s}$ to be 86,879-by-8,069; representing the 86,879 messages in our sample that contain 8,069 unique bigrams.

We construct our final dataset by then merging a number of controls to our matrix of bigram counts. In addition to the controls documented in Section 3.2, we add dummies for the total number of messages sent by that seller, a variable representing the message length - which we measure by the number of tokens in the raw messageand the log of the offer price attached to the message. We then have 242 controls included in our analysis. 


\section{The DMR Model}

Our main variable of interest is the message number sent by that seller. Here, we hope to further understand the bigrams that are correlated to seller experience. To do this, we implement a distributed multinomial model from Taddy (2015). This model was additionally used as the preferred specification in Gentzkow et al. (2019b); in this paper, the authors analyze congressional speeches from 1873 to 2016 in order to estimate the trends in partisanship.

In implementing this model, we are first assuming that our bigrams counts are being generated by the multinomial distribution. ${ }^{26}$ Specifically, the counts in each message $m$ are drawn by the multinomial distribution with parameters $n_{m}=\sum_{j} c_{m j}$, the total number of bigrams said in message $m$, and probability vector $\mathbf{p}_{m}$, indicating the probability of including each bigram conditional on the controls specified in the previous section. To compute these probability vectors, we we would then estimate

$$
p_{m j}=\frac{\exp \left(\zeta_{m j}\right)}{\sum_{l=1} \exp \left(\zeta_{m l}\right)}, \text { where } \zeta_{m j}=\alpha_{j}+\boldsymbol{\beta}_{j} \mathbf{v}_{m}+\rho_{j} x_{m}
$$

Here, the vector $\mathbf{v}_{m}$ represents our set of controls for message $m$; additionally, message number, our proxy for experience, is denoted by $x_{m}$.

Rather than running a computationally intensive multinomial logistic regression, Taddy (2015) notes that we can instead assume $c_{m j} \sim \operatorname{Pois}\left(\exp \left[\mu_{m}+\alpha_{j}+\boldsymbol{\beta}_{j} \mathbf{v}_{m}+\rho_{j} x_{m}\right]\right)$ where we fix $\mu_{m}$ as $\hat{\mu}_{m}=\log \left(n_{m}\right)$. This allows us to run separate Poisson regressions for each bigram.

For each Poisson regression we then estimate the coefficient on message number for bigram $j$ by minimizing

$$
\sum_{m}\left[n_{m} \exp \left(\zeta_{m j}\right)-c_{m j}\left(\zeta_{m j}\right)\right]+\lambda\left[\frac{1}{\tau} \sum_{k}\left|\beta_{j k}\right|+\left|\rho_{j}\right|\right] \cdot{ }^{27}
$$

In this equation, we include L1 regularization through the penalizing term, $\lambda$, which reduces the number of features in our model by shrinking the coefficients $\boldsymbol{\beta}_{j}$ and

\footnotetext{
${ }^{26}$ This assumes that each bigram in a message is independently generated. While this assumption is undoubtedly violated, assuming a multinomial distribution for text is common practice (see Taddy (2015), Gentzkow et al. (2019a)).

${ }^{27}$ Note that the coefficients for our controls and message number are standardized so that they have a standard deviation of one.
} 
$\rho_{j}$ toward zero. For this exercise, we selected the $\lambda$ that minimizes the mean outof-sample deviance using 10 -fold cross-validation $(\mathrm{CV}) .{ }^{28}$ We chose to incorporate variable selection into our model in order to generate a more interpretable output and to avoid over-fitting our data. Importantly, we suspect that there are many bigrams in our dataset that have no or little relation to seller experience. This penalizing term then introduces sparsity into our model and will shrink the coefficients for message number to zero if they have little out-of-sample predictive power for those bigrams.

Next, we vary the level of $\tau$. Setting $\tau=0.1,0.5,1$, and 3 changes the extent of the penalty the model imposes on the set of controls. A smaller $\tau$ means that we will be incorporating a larger penalty on our controls rather than message number; while a larger $\tau$ will reduce the collinearity between our controls and variable of interest as we inflict a lower penalty on $\boldsymbol{\beta}_{j}$.

\section{Experience Results}

We present our results in three separate tables: First, Table A-7 includes the top and bottom 10 bigrams determined by the coefficients on message number for different levels of $\tau$. Next, we generate an estimated experience score for each message. This is simply the summation of the bigram coefficients generated by our model for each message. We then present the top and bottom scoring messages in Tables A-8 and A-9.

In all three tables, we blocked out any potentially identifying information. This includes names, company names, addresses, and emails. We used Google Translate's API for the translations from German to English. In some of cases, we found that using the web version of Google Translate produced a different result than the API; in these cases, we used the translation from the web if we found that it presented a more interpretable result. Finally, in Table A-7, note that these translations are generated on the stemmed bigrams; this will slightly change the translation from the translation of the words actually used in the message. See the next two tables for translations on the raw messages themselves.

The second column of these tables indicates the number of nonzero coefficients for message number. Here, we can see that as $\tau$ increases in size, our controls absorb a

\footnotetext{
${ }^{28}$ We ran the same model using 5 -fold $\mathrm{CV}$ and found similar results. Results can be shown upon request.
} 
larger amount of the variation in $\rho_{j}$, effectively shrinking a growing number of these coefficients to zero. Additionally, we should note that the top and bottom bigrams and messages are fairly robust to the value we set for $\tau$.

In Table A-7, within the top bigrams by message number, we see a lot of farewells and message sign-offs. For instance, "mfg" means "best regards" in German and is a common way to end communication in electronic messages - we see this in two separate bigrams in our $\tau=3$ specification. Similarly, "lg" shows up for all values of $\tau$ and is another common farewell in German.

In our list of the bottom 10 bigrams, we don't see any farewells, but a few greetings do appear: "greeting [NAME]" and "dear interested person". The efficacy of greetings, farewells, and gratitude in successful bargaining and negotiations is unclear from the previous literature as some authors find that friendly communication will lead to more trust and reciprocity in bargaining and, as a result, better outcomes (Hine et al. (2009), Kopelman et al. (2006)); alternatively, others have found communicating in firm, and potentially more aggressive, tones are good strategies in negotiations (Jeong et al. (2019), Belkin et al. (2013)).

In Table A-8, the top scoring message for all versions besides $\tau=3$, displays one interesting strategy that sellers may be adopting: Here, we see a seller justifying their cost through explaining that there is a "10\% ebay commission, shipping, etc." In a similar fashion, we also see sellers justifying charging a higher price in the auction due to the "sales commission" and through the fact that the item is already discounted.

Alternatively, in Table A-9, sellers seem to be more often justifying the costs of the item through either the price they paid for the item or by providing details on the item: the "jacket [is] made of real leather," the "book was purchased completely new," the wardrobe is "very beautiful." Additionally, the sellers appear to be less assertive in their messaging through their usage of "would be happy," "I hope they can also make friends with my proposal," "if that's okay."

\section{Message Success Robustness}

In this section, we replicate our analysis from Section 6 for the full set of sellers and for the set of sellers that sent fewer than 11 messages. Table A-10 presents the results from regressing message success on the cosine similarity of each message and the set of week 10 messages for our entire sample. Moreover, Table A-11 includes the same 
regression excluding sellers that sent 11 or more messages from the analysis. Our results are somewhat weaker when including the full set of sellers. Moreover, our coefficient on our similarity measure is negative and insignificant when including seller fixed effects. The results restricting to sellers with fewer than 11 messages largely align with our previous findings. 


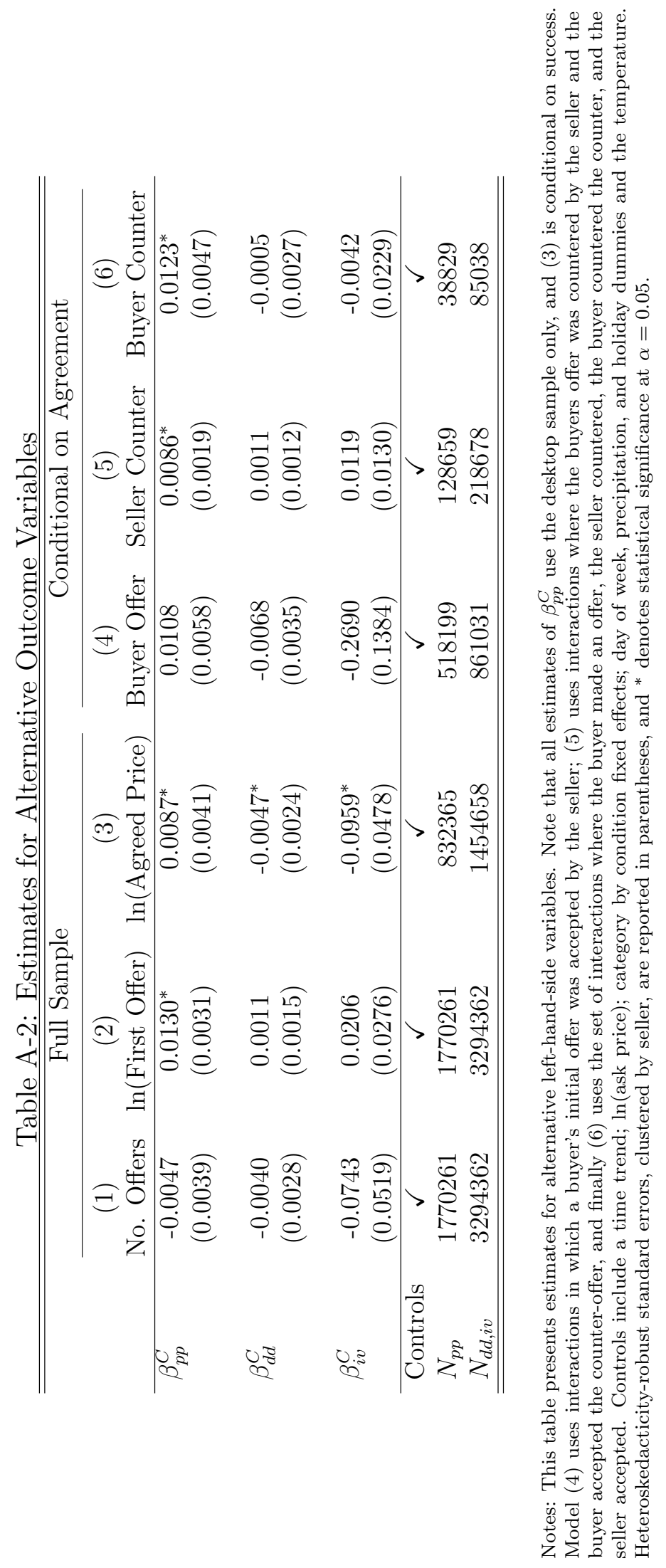

Appendix-14 
Table A-3: Estimates by Asking Price Range

\begin{tabular}{lcc}
\hline \hline & $(1)$ & $(2)$ \\
\hline Ask Price in $(\$ 0, \$ 50)$ & $0.0945^{*}$ & $0.1044^{*}$ \\
& $(0.0366)$ & $(0.0362)$ \\
Ask Price in $[\$ 50, \$ 150)$ & $0.0957^{*}$ & $0.0898^{*}$ \\
& $(0.0354)$ & $(0.0351)$ \\
Ask Price in $[\$ 150, \$ 250)$ & 0.0387 & 0.0241 \\
& $(0.0490)$ & $(0.0485)$ \\
Ask Price $\geq \$ 250$ & 0.0284 & 0.0351 \\
& $(0.0321)$ & $(0.0318)$ \\
\hline Controls & & $\checkmark$ \\
\hline \hline
\end{tabular}

Notes: This table presents estimates of $\beta_{i v}^{C}$ for four different price ranges. Note that price ranges are defined in USD. All parameters of the model are estimated independently for each coefficient estimate. In model (1), no controls are included, while in model (2), the full set of controls detailed in Table 3 are included. Heteroskedacticity-robust standard errors, clustered by seller, are reported in parentheses, and * denotes statistical significance at $\alpha=0.05$.

Table A-4: Estimates by Sample Window

\begin{tabular}{lcccccc}
\hline \hline & $(+/-2)$ & $(+/-3)$ & $(+/-4)$ & $(+/-5)$ & $(+/-6)$ & $(+10 /-7)$ \\
\hline$\beta_{p p}^{C}$ & -0.0008 & 0.0026 & 0.0023 & $0.0042^{*}$ & $0.0036^{*}$ & 0.0016 \\
& $(0.0030)$ & $(0.0022)$ & $(0.0019)$ & $(0.0018)$ & $(0.0017)$ & $(0.0016)$ \\
$\beta_{d d}^{C}$ & 0.0017 & 0.0025 & $0.0042^{*}$ & $0.0047^{*}$ & $0.0040^{*}$ & $0.0034^{*}$ \\
& $(0.0017)$ & $(0.0014)$ & $(0.0012)$ & $(0.0011)$ & $(0.0010)$ & $(0.0009)$ \\
& & & & & & \\
$\beta_{i v}^{C}$ & 0.0344 & 0.0476 & $0.0773^{*}$ & $0.0865^{*}$ & $0.0731^{*}$ & $0.0597^{*}$ \\
& $(0.0337)$ & $(0.0265)$ & $(0.0226)$ & $(0.0204)$ & $(0.0190)$ & $(0.0165)$ \\
\hline Controls & $\checkmark$ & $\checkmark$ & $\checkmark$ & $\checkmark$ & $\checkmark$ & $\checkmark$ \\
$\mathrm{N}$ & 1649026 & 2432528 & 3294362 & 4091076 & 4924926 & 6766228 \\
\hline \hline
\end{tabular}

Notes: This table presents estimation results mirroring Table 3 varying the sample inclusion window. Each cell is the result of an independent regression. Each row represents a different estimation strategy: respectively, pre-post, differences-in-differences, and instrumental variables. Each column represents a different sample, where the column header indicates the number of weeks before and the number of weeks after May 23, 2016. Heteroskedacticity-robust standard errors, clustered by seller, are reported in parentheses, and * denotes statistical significance at $\alpha=0.05$. 
Table A-5: Estimates with Seller Fixed Effects

\begin{tabular}{lcccc}
\hline \hline & $(1)$ & $(2)$ & $(3)$ & $(4)$ \\
& Desktop & Mobile & Differences & IV \\
\hline $\mathbb{1}$ (Post) & 0.0024 & 0.0024 & 0.0008 & 0.0011 \\
& $(0.0016)$ & $(0.0018)$ & $(0.0013)$ & $(0.0012)$ \\
& & & & \\
$\mathbb{1}$ (Desktop) & & & $0.0355^{*}$ & $0.0355^{*}$ \\
& & & $(0.0008)$ & $(0.0008)$ \\
$\mathbb{1}$ (Post) $\cdot \mathbb{1}$ (Desktop) & & & & \\
& & & $0.0027^{*}$ & \\
$\mathbb{1}$ (Message) & & & $(0.0011)$ & \\
& & & & $0.0561^{*}$ \\
Controls & & & & $(0.0222)$ \\
Seller FE & $\checkmark$ & $\checkmark$ & $\checkmark$ & $\checkmark$ \\
$\mathrm{N}$ & $\checkmark$ & $\checkmark$ & $\checkmark$ & $\checkmark$ \\
\hline \hline
\end{tabular}

Notes: This table replicates models with the full set of controls from Table 3, where we now also include seller fixed effects. Models (1) and (2) are pre-post estimates for the desktop and mobile samples, respectively, while models (3) and (4) are differences-in-differences and IV estimates, respectively. Standard errors are reported in parentheses, and * denotes statistical significance at $\alpha=0.05$. 
Table A-6: Example messages

Censored Message Excerpts (from Google Translate)

This is unfortunately the best price we can offer you.

Hello, under it does not go unfortunately. MfG

Hello, would like to ask if you would sell the article also for 15, - Euro. LG S. [NAME]

I do not go down sry

Incl. Shipping.

Hello dear [PRODUCT]-interested. What would happen if we met in the middle? There are also figures outside of the electric carousel. Is that OK? Friendly Greetings [NAME]

Hello that would be my last price

let's meet in the middle?

This is definitely the minimum

And they have not sold the vest until today, beat them to 49.00 euros is a good price and they finally have their rest. . . Greetings

I would pay 105 euros if the [PRODUCT] was bought not more than 6 months ago and the original invoice with rest guarantee is available and included. To compare: New at Voelkner currently 119,04 with 2 years warranty! MfG

25 Euro since articles new \& unused.

I intend not to issue any higher offer.

Since the hard disk is missing! it's alright?

With the purchase of several [PRODUCT], you save more - you pay postage only once.

not less....

... rarely laughed so much!

VERY SIMPLY

Would be glad if you accept this proposal.

Unfortunately, more I can not afford $\mathrm{mfg}$

I'll buy the [PRODUCT]!

This is a super cheap price!!

Notes: Here we present a curated set of messages by both buyers and sellers, translated by Google Translate from the original German. We have censored any potentially identifying information, in particular individual and product names. 


\section{Figure A-3: Heat Maps and Off-Diagonal Figures for Repeat Buyers}

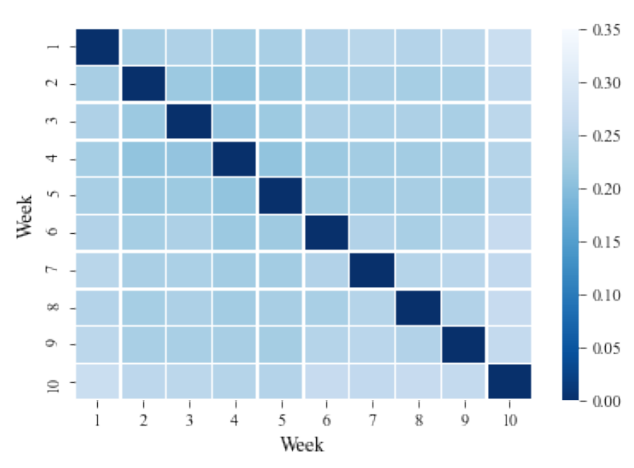

(a) $2+$ Messages

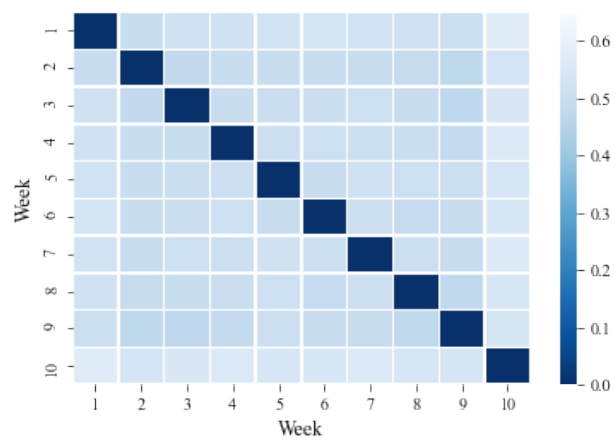

(c) $3+$ Messages

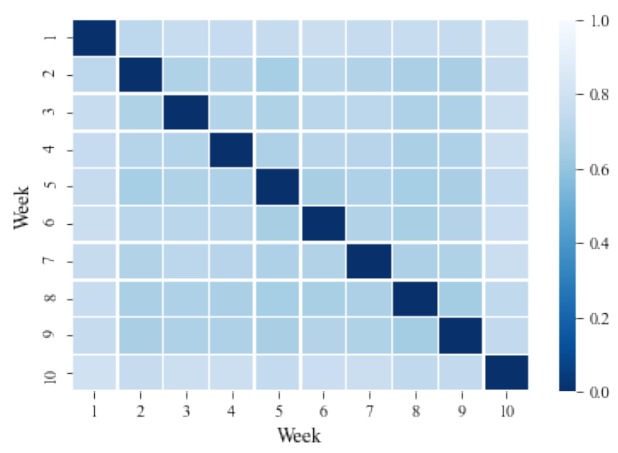

(e) $4+$ Messages

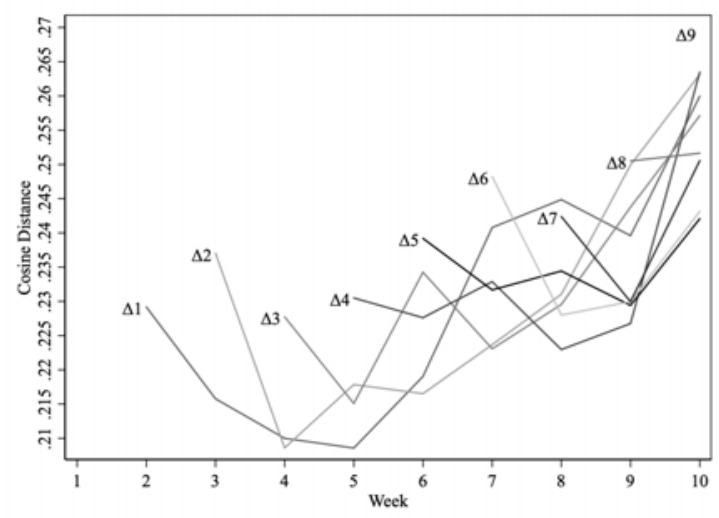

(b) $2+$ Messages

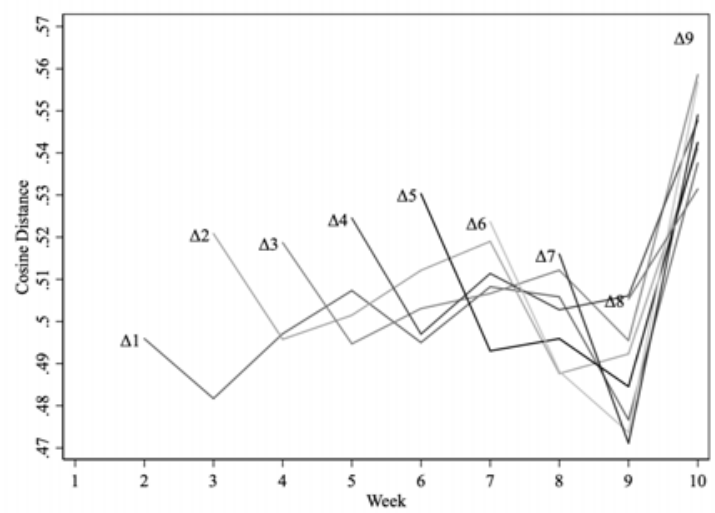

(d) $3+$ Messages

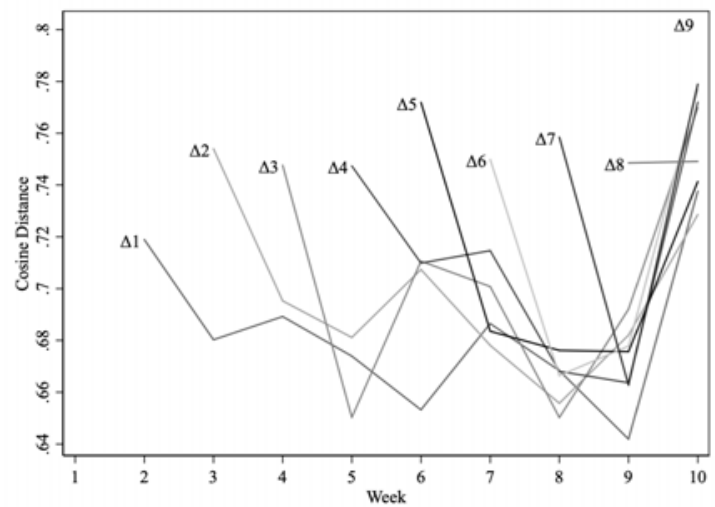

(f) $4+$ Messages

Notes: This figure depicts heat map results and plots along the off-diagonals of those heat maps representing the cosine distance of message bigrams across the ten weeks following May 25, 2016 for different subgroups of buyers. Panels (a) and (b) shows the results for buyers that have sent two or more messages during our sample period, Panels (b) and (c) shows the same results for buyers that sent more than 3 messages, Panel (d) and (e) display the results for buyers that appear four or more times in our messaging dataset. 


\section{Figure A-4: Heat Maps and Off-Diagonal Figures for Repeat Sellers}

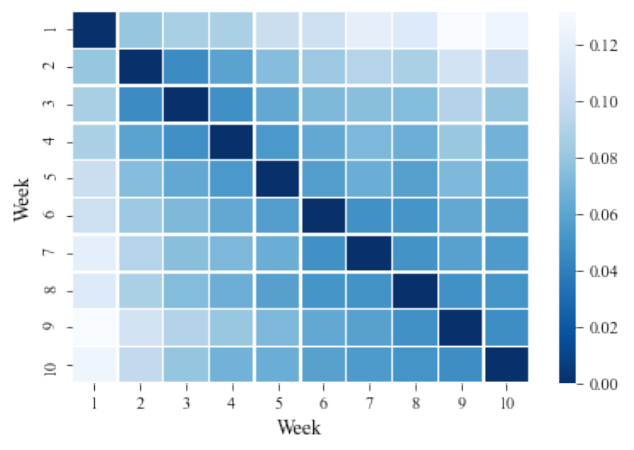

(a) $2+$ Messages

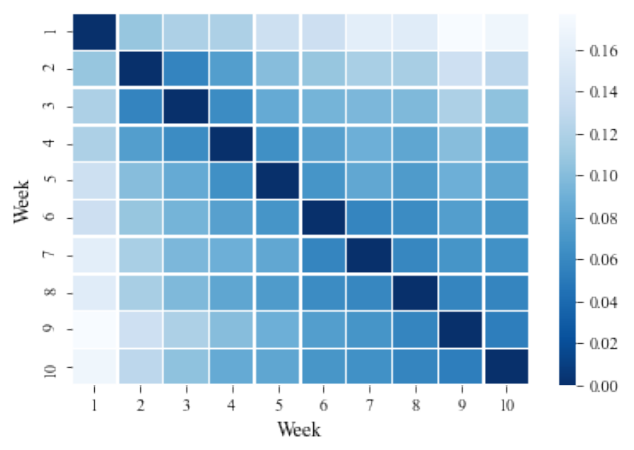

(c) $3+$ Messages

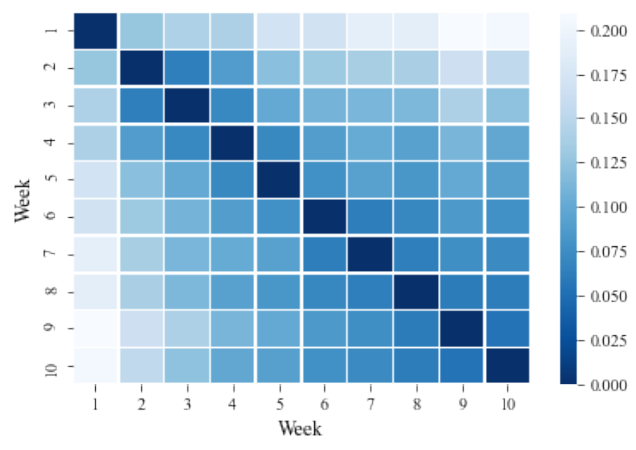

(e) $4+$ Messages

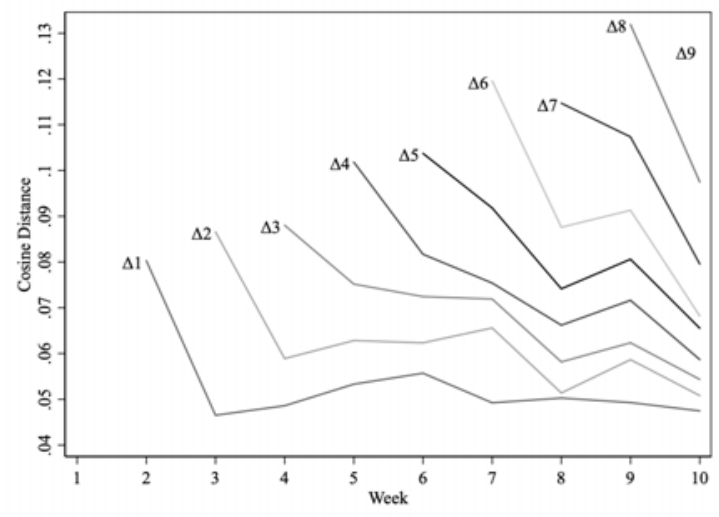

(b) $2+$ Messages

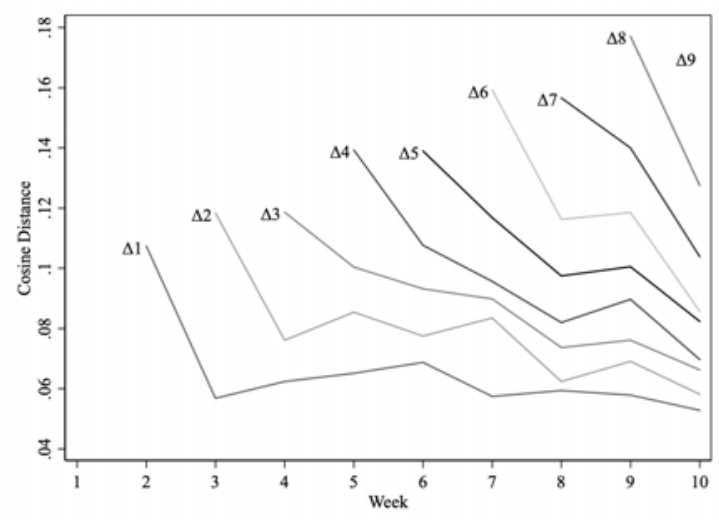

(d) $3+$ Messages

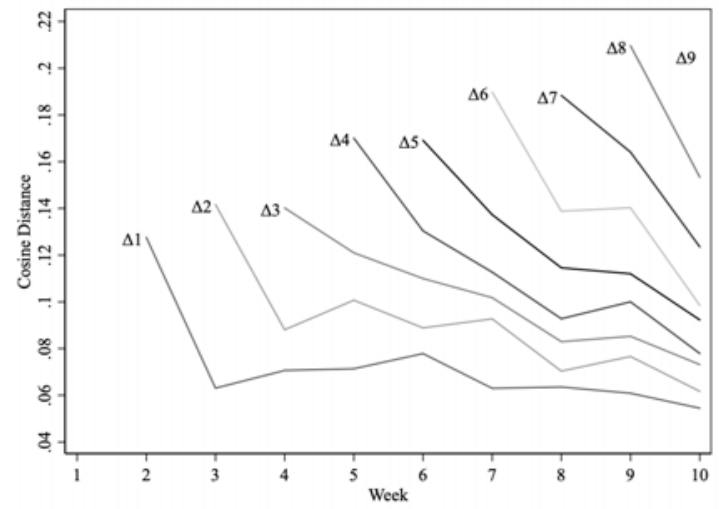

(f) $4+$ Messages

Notes: This figure depicts heat map results and plots along the off-diagonals of those heat maps representing the cosine distance of message bigrams across the ten weeks following May 25, 2016 for different subgroups of sellers. Panels (a) and (b) shows the results for sellers that have sent two or more messages during our sample period, Panels (b) and (c) shows the same results for sellers that sent more than 3 messages, Panel (d) and (e) display the results for sellers that appear four or more times in our messaging dataset. 
Figure A-5: Buyers and Sellers with No Experience

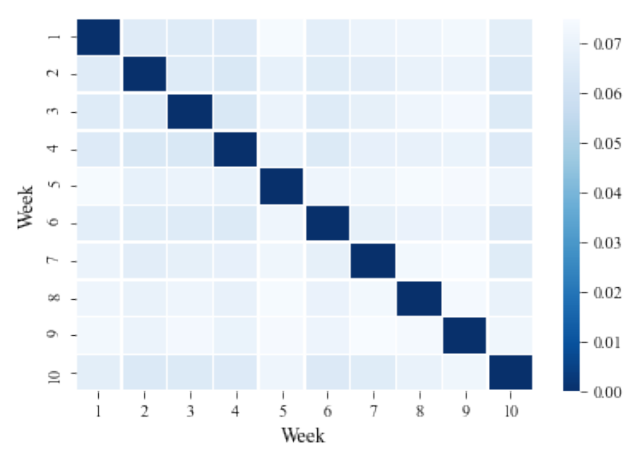

(a) Buyer Heat Map

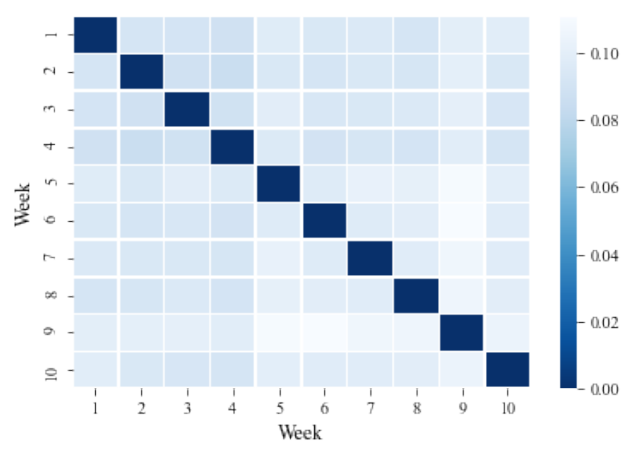

(c) Seller Heat Map

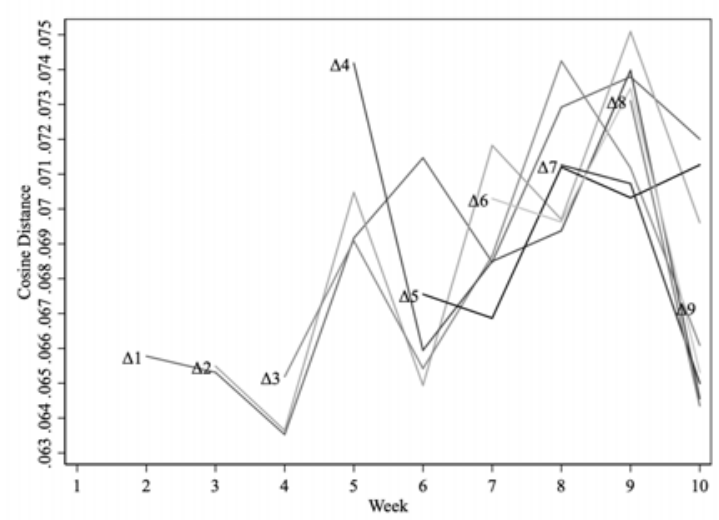

(b) Buyer Convergence

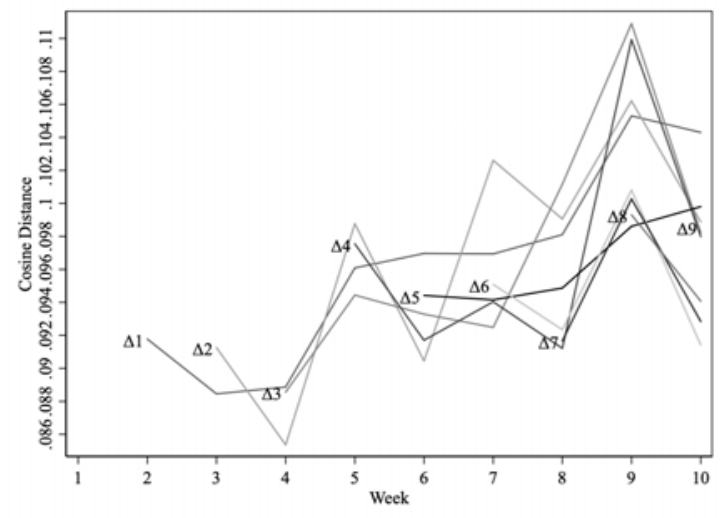

(d) Seller Convergence

Notes: This figure depicts heat map results and plots along the off-diagonals of those heat maps representing the cosine distance of message bigrams across the ten weeks following May 25, 2016 for buyers and sellers in our messaging dataset that only sent one message. Panels (a) and (b) shows the results for buyers who sent one message within our sample period and Panels (b) and (c) show the same results for sellers. 
Figure A-6: The Bottom Gradient for Buyers and Sellers with Different Experience Levels

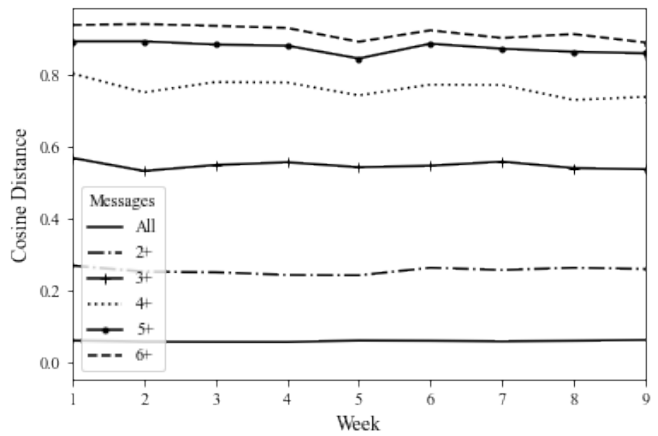

(a) Buyer

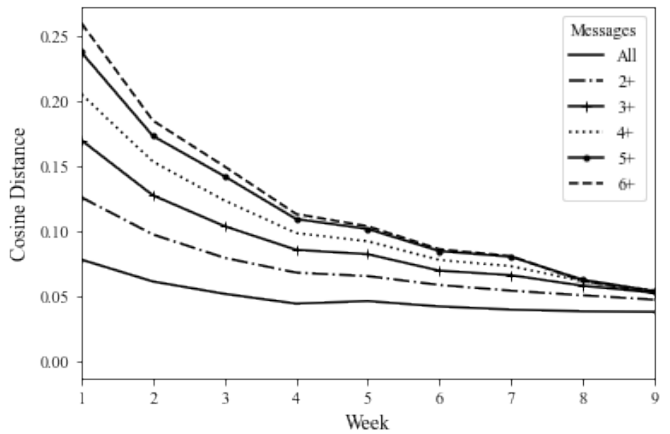

(b) Seller

Notes: This figure presents the cosine distance between the messages sent in weeks $\mathrm{x}$ and 10 for buyers, Panel (a), and sellers, Panel (b). Each panel is cut by groups, where All represents our results from buyer/seller messages for our entire sample of buyers/sellers, $2+$ from our sample of messages sent by buyers/sellers who sent 2 or more messages, $3+$ from our sample of messages sent by buyers/sellers who sent 3 or more messages, and so on. 
Figure A-7: Total Messages by Week for Buyers and Sellers

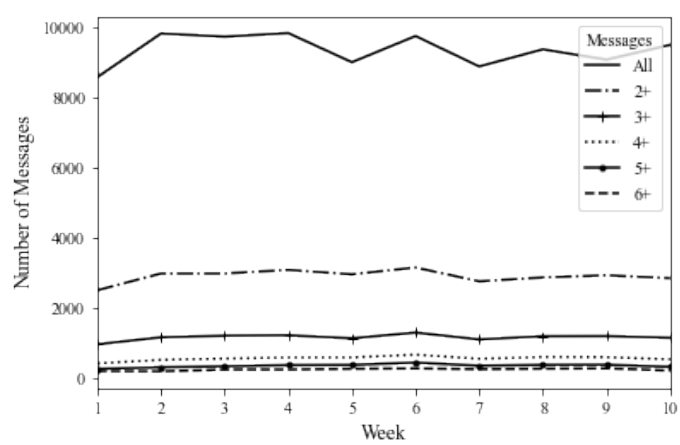

(a) Buyer

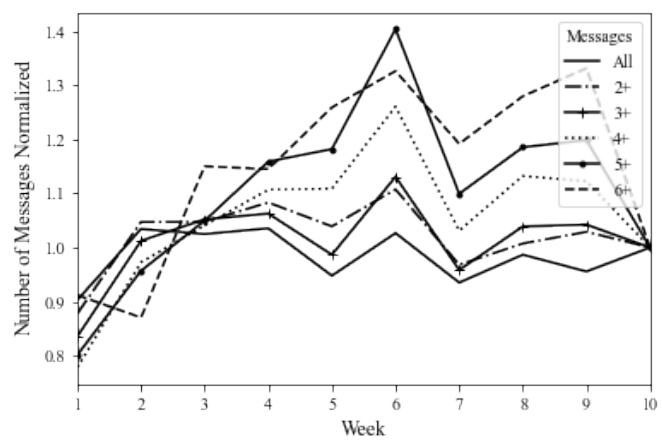

(c) Buyer Nomalized

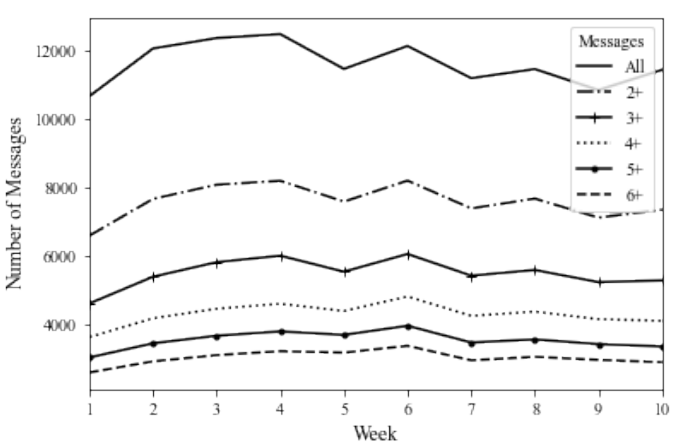

(b) Seller

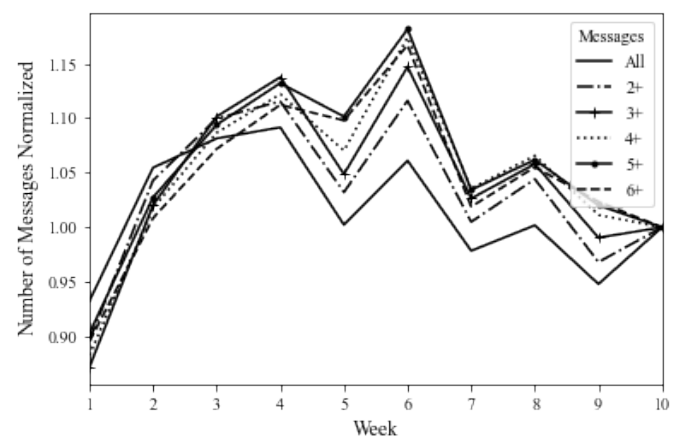

(d) Seller Normalized

Notes: This figure presents the total number of messages sent by buyers, Panel (a), and sellers, Panel (b), by week. Panel (c) and Panel (d) are the buyer and seller number of messages scaled by the number of messages in week 10. Each panel is cut by groups, where All represents our results from buyer/seller messages for our entire sample of buyers/sellers, $2+$ from our sample of messages sent by buyers/sellers who sent 2 or more messages, $3+$ from our sample of messages sent by buyers/sellers who sent 3 or more messages, and so on. 


\section{Table A-7: Top and Bottom Bigrams Correlated with Message Number}

\begin{tabular}{lll}
\hline$\tau$ & Nonzero & Bigrams \\
\hline \multirow{4}{*}{152} & Top 10 \\
& thanks in advance mfg; award-understand; understand beg; without eba; low \\
& number of pieces; pray thanks; discount safeguarded; lg [NAME]; mfg sale; known \\
& does \\
& dank vorausmfg; preis versteh; versteh bitt; ohn eba; gering stuckzahl; bitt dank; rabatt \\
& gewahrt; lg [NAME]; mfg verkauf; kund tut \\
& \\
& so far; thanks in advance mfg; beg functional scope of supply; observe scope \\
& of delivery; Regular price insof; lg [NAME]; down selling price; shipping cost \\
& adjusted; award-understand; low number of pieces \\
& insof schon; dank vorausmfg; bitt funktionslieferumfang; funktionslieferumfang beacht; \\
& verkaufspreis insof; lg [NAME]; runt verkaufspreis; versandkost angepasst; preis versteh; ger-
\end{tabular}

ing stuckzahl

$0.53603 \quad$ beg functional scope of supply; observe scope of delivery; Regular price insof; thanks in advance mfg; so far; down selling price; lg [NAME]; award-understand; shipping cost adjusted; discount safeguarded

bitt funktionslieferumfang; funktionslieferumfang beacht; verkaufspreis insof; dank vorausmfg; insof schon; runt verkaufspreis; lg [NAME]; preis versteh; versandkost angepasst; rabatt gewahrt

$0.16290 \quad$ Regular price insof; beg functional scope of supply; so far; observe scope of delivery; lg [NAME]; shipping cost adjusted; down selling price; rather tight; Newly listed; sale mfgruss

verkaufspreis insof; bitt funktionslieferumfang; insof schon; funktionslieferumfang beacht; lg [NAME]; versandkost angepasst; runt verkaufspreis; recht knapp; neu eingestellt; verkauf mfgruss

\section{Bottom 10}

$3152 \quad$ counter already; gb memory card; miss it not; from august; for figure; sale however; greeting [NAME]; over-looking payment method; ready priced; far kart entgeg schon; gb speicherkart; verpass nicht; ab august; fur figur; verkauf jedoch; gruss [NAME]; uberweis zahlungsmethod; bereit preislich; weit kart

$11730 \quad$ counter already; is set; gb memory card; ready priced; greeting [NAME]; just give; extremely fair; suggest price proposal; not worn; month old entgeg schon; eingestellt wurd; gb speicherkart; bereit preislich; gruss [NAME]; geb einfach; ausserst fair; preisvorschlag ordnung; nicht getrag; monat alt

$0.53603 \quad$ woman has; is set; counter already; day would like; interess shipping; cm wide; extremely fair; natural possible; ready priced; just give

freu schon; eingestellt wurd; entgeg schon; tag mocht; interess versand; cm breit; ausserst fair; natur moglich; bereit preislich; geb einfach

$0.16290 \quad$ woman has; cm wide; day would like; under asking price; new mature; extremely fair; dear interested person; is set; brand new unworn; rims tires

freu schon; cm breit; tag mocht; unt preisvorstell; neu reif; ausserst fair; lieb interessentin; eingestellt wurd; nagelneu ungetrag; felg reif

Notes: This table includes the top and bottom ten bigrams in both English and the original German ranked by our coefficients on message number for different levels of $\tau$. The second column in the table indicates the amount of message number coefficients that are not penalized to zero for that value of $\tau$. 
Table A-8: Top Messages

\begin{tabular}{lll}
\hline$\tau$ & Nonzero & Top Messages \\
\hline 3 & 152 & 1. this is our lowest price, please understand, many thanks in advance ... mfg (60) \\
& dies ist unser niedrigster preis, verstehen sie bitte, vielen dank im voraus...mfg \\
& 2. hello, this product we played $20 \%$ discount, and the price is already miss you please understand, \\
& many thanks in advance ... mfg (20) \\
& hallo, dieses produkt haben wir $20 \%$ rabatt gespielt, und der preis ist bereits mit verlust verstehen sie bitte, vielen \\
& dank im voraus...mfg \\
& 3. they have slight problems when assessing the price but I understand that! (380) \\
& sie haben leichte probleme beim einschätzen des preises aber ich verstehe das!
\end{tabular}

11730 1. thank you for your price suggestion, but unfortunately it is below my purchase price: $10 \%$ ebay commission, shipping, etc. are still going down and the selling price is calculated quite tightly. please also note the scope of functions / scope of delivery! kind regards (40)

danke für ihren preisvorschlag, liegt aber leider unter meinem einkaufspreis: 10\% ebay-provision, versand usw. gehen ja auch noch runter und der verkaufspreis ist insofern schon recht knapp kalkuliert. bitte auch funktions/lieferumfang beachten! mfg

2. this is our lowest price, please understand, many thanks in advance ... mfg (60)

dies ist unser niedrigster preis, verstehen sie bitte, vielen dank im voraus...mfg

3. hello, this product we played $20 \%$ discount, and the price is already miss you please understand, many thanks in advance ... mfg (20)

hallo, dieses produkt haben wir $20 \%$ rabatt gespielt, und der preis ist bereits mit verlust verstehen sie bitte, vielen dank im voraus...mfg

0.53603 1. thank you for your price suggestion, but unfortunately it is below my purchase price: $10 \%$ ebay commission, shipping, etc. are still going down and the selling price is calculated quite tightly. please also note the scope of functions / scope of delivery! kind regards (40)

danke für ihren preisvorschlag, liegt aber leider unter meinem einkaufspreis: $10 \%$ ebay-provision, versand usw. gehen ja auch noch runter und der verkaufspreis ist insofern schon recht knapp kalkuliert. bitte auch funktions/lieferumfang beachten! mfg

2. this is our lowest price, please understand, many thanks in advance ... mfg (60)

dies ist unser niedrigster preis, verstehen sie bitte, vielen dank im voraus...mfg

3. hello, this product we played $20 \%$ discount, and the price is already miss you please understand, many thanks in advance... mfg (20)

hallo, dieses produkt haben wir $20 \%$ rabatt gespielt, und der preis ist bereits mit verlust verstehen sie bitte, vielen dank im voraus...mfg

0.16290 1. thank you for your price suggestion, but unfortunately it is below my purchase price: $10 \%$ ebay commission, shipping, etc. are still going down and the selling price is calculated quite tightly. please also note the scope of functions / scope of delivery! kind regards (40)

danke für ihren preisvorschlag, liegt aber leider unter meinem einkaufspreis: 10\% ebay-provision, versand usw. gehen ja auch noch runter und der verkaufspreis ist insofern schon recht knapp kalkuliert. bitte auch funktions/lieferumfang beachten! $\mathrm{mfg}$

2. to get big discount, please send inquiry to delivery address directly to our e-mail. thank you and friendly greetings, [NAME] [NAME] [company] [address] celle phone: xxxxx xxxxxxx email: email@email.de (100)

um großer rabatt zu bekommen, bitte senden sie anfrage mit lieferadresse direkt auf unsere e-mail. danke und freundliche grüße, [NAME] [NAME] [company] [address] celle telefon: xxxxx-xxxxxxx email: email@email.de

3. hello, thank you very much for your interest! I can offer you the lock for $80+$ postage if we do not go to the auction. I pass the sales commission on to you. just send me a message! best regards (90)

hallo, vielen dank für ihr interesse! ich kann ihnen das schloß für $80+$ porto anbieten, wenn wir auf die auktion verzichten. die gesparte verkaufsprovision gebe ich so an sie weiter. senden sie mir hierzu einfach eine nachricht! beste grüße

Notes: This table presents the top three messages based on the summation of the coefficients on message number for each bigram in the message for different levels of $\tau$. The second column in the table indicates the amount of message number coefficients that are not penalized to zero. We include the listing price in euros rounded to the nearest tens place in parenthesis next to each message. Finally, the German version of the message is included below each English translation. 


\section{Table A-9: Bottom Messages}

\begin{tabular}{ll}
\hline$\tau \quad$ Nonzero & Bottom Messages \\
\hline $3 \quad 152$ & 1. good morning, thank you for your best offer. like I get to meet them on my original award, 50 I \\
& can still give so. so we would be able to meet in the middle us virtually. with the request for your \\
& understanding! $m$ (400) \\
& guten morgen, herzlichen dank für ihren preisvorschlag. gerne komme ich ihnen auf meinen ursprünglichen preis \\
& entgegen, 50 kann ich schon noch nachgeben. so würden wir uns quasi in der mitte treffen können. mit der bitte \\
& um verständnis! m \\
& 2. I just discovered a very small hole on the back, so the price is a little bit more accommodating \\
& ... best regards! (20) \\
& auf der rückseite habe ich gerade ein ganz kleines löchlein entdeckt, daher komme ich im preis etwas entgegen ... . \\
& schönen gruß! \\
& 3. good day, many thanks for your interest in the wardrobe stand of classicon. it is a very beautiful \\
& piece of furniture in excellent condition. like I get to meet them in the award. beautiful greetings to \\
& jump! (1350) \\
& guten tag, vielen dank für ihr interesse an dem garderobenständer von classicon. es handelt sich um ein sehr schönen \\
& möbelstück in hervorragendem zustand. gerne komme ich ihnen im preis entgegen. schöne grüße nach springe!
\end{tabular}

117301 1. love potential customer, I like to go even at 55 down, but since that is not further jacket made of real leather and as well as not being worn. I ask for understanding and would be happy about their purchase still very! nice greetings, [NAME] [NAME] (60)

liebe interessentin, ich gehe gerne noch auf 55 runter, weiter jedoch nicht, da die jacke aus echtleder und so gut wie nicht getragen ist. ich bitte um verständnis und würde mich über ihren kauf trotzdem sehr freuen! schöne grüße, [NAME] [NAME]

2. Suggest Price is ok, but please note notebook holidays. Shipping only possible again from 19:08. if that's okay, please buy. (10)

preisvorschlag ist in ordnung, bitte aber urlaubsnotiz beachten. versand erst wieder ab dem 19.08 möglich. wenn das okay ist, bitte kaufen.

3. since the book was purchased completely new and is not available in the book trade, I ask for understanding that I no longer priced under these above-mentioned Suggest Price can go. I hope they can also make friends with my proposal against. (10)

da das buch völlig neu gekauft wurde und im buchhandel nicht erhältlich ist, bitte ich um verständnis, das ich preislich nicht mehr unter diesen o.g. preisvorschlag gehen kann. ich hoffe, sie können sich mit meinem gegenvorschlag auch anfreunden.

0.53603 1. love potential customer, I like to go even at 55 down, but since that is not further jacket made of real leather and as well as not being worn. I ask for understanding and would be happy about their purchase still very! nice greetings, [NAME] [NAME] (60)

liebe interessentin, ich gehe gerne noch auf 55 runter, weiter jedoch nicht, da die jacke aus echtleder und so gut wie nicht getragen ist. ich bitte um verständnis und würde mich über ihren kauf trotzdem sehr freuen! schöne grüße, [NAME] [NAME]

2. I myself had EUR 80.00 plus shipping paid now for it: shipping included insured EUR 70.00. I would be happy if the beautiful part is in good hands! kind regards! (80)

ich selbst hatte euro 80,00 plus versand bezahlt, für sie nun: euro 70,00 inklusive versicherter versand. ich würde mich freuen, wenn das schöne teil in gute hände kommt! herzliche grüße!

3. since the book was purchased completely new and is not available in the book trade, I ask for understanding that I no longer priced under these above-mentioned Suggest Price can go. I hope they can also make friends with my proposal against. (10)

da das buch völlig neu gekauft wurde und im buchhandel nicht erhältlich ist, bitte ich um verständnis, das ich preislich nicht mehr unter diesen o.g. preisvorschlag gehen kann. ich hoffe, sie können sich mit meinem gegenvorschlag auch anfreunden.

$0.16290 \quad$ 1. love potential customer, I like to go even at 55 down, but since that is not further jacket made of real leather and as well as not being worn. I ask for understanding and would be happy about their purchase still very! nice greetings, [NAME] [NAME] (60)

liebe interessentin, ich gehe gerne noch auf 55 runter, weiter jedoch nicht, da die jacke aus echtleder und so gut wie nicht getragen ist. ich bitte um verständnis und würde mich über ihren kauf trotzdem sehr freuen! schöne grüße, nicht getragen ist.

2. I myself had EUR 80.00 plus shipping paid now for it: shipping included insured EUR 70.00. I would be happy if the beautiful part is in good hands! kind regards! (80)

ich selbst hatte euro 80,00 plus versand bezahlt, für sie nun: euro 70,00 inklusive versicherter versand. ich würde mich freuen, wenn das schöne teil in gute hände kommt! herzliche grüße!

3. sorry, but there is my lowest painful limit because the shoes have well over EUR 150 cost. I would be happy if the beautiful shoes treat anyway. me they are unfortunately too small. (60)

sorry, aber da ist meine unterste schmerzgrenze, da die schuhe weit über eur 150 gekostet haben. würde mich freuen, wenn sie sich die schönen schuhe trotzdem gönnen. mir sind sie leider zu klein.

Notes: This table presents the bottom three messages based on the summation of the coefficients on message number for each bigram in the message for different levels of $\tau$. The second column in the table indicates the amount of message number coefficients that are not penalized to zero. We include the listing price in euros rounded to the nearest tens place in parenthesis next to each message. Finally, the German version of the message is included below each English translation. 
Table A-10: Message Success (All Sellers)

\begin{tabular}{lccc}
\hline \hline & $(1)$ & $(2)$ & $(3)$ \\
\hline $\operatorname{Sim}(m$, week 10) & $0.0456^{*}$ & $0.0345^{*}$ & -0.0277 \\
& $(0.0168)$ & $(0.0170)$ & $(0.0352)$ \\
Message Length & & & \\
& & $0.0009^{*}$ & 0.0002 \\
& & $(0.0002)$ & $(0.0004)$ \\
\hline $\mathrm{N}$ & 113600 & 113600 & 73839 \\
Controls & $\checkmark$ & $\checkmark$ & $\checkmark$ \\
Seller FE & & & $\checkmark$ \\
\hline \hline
\end{tabular}

Notes: This table presents our results from regressing message success onto a measure of seller experience. Sim $(m$, week 10) is the cosine similarity between a message and the set of week 10 messages. All models include our main set of controls: time trend; $\ln$ (ask price); category by condition fixed effects; day of week, precipitation, holiday dummies, and the temperature. Model (3) includes seller fixed effects. Robust standard errors are reported in parentheses and * denotes statistical significance at $\alpha=0.05$.

Table A-11: Message Success (Sellers with Fewer than 11 Messages)

\begin{tabular}{lccc}
\hline \hline & $(1)$ & $(2)$ & $(3)$ \\
\hline $\operatorname{Sim}(m$, week 10) & $0.0589^{*}$ & $0.0485^{*}$ & 0.0671 \\
& $(0.0235)$ & $(0.0236)$ & $(0.0457)$ \\
& & & \\
Message Length & & $0.0014^{*}$ & 0.0003 \\
& & $(0.0002)$ & $(0.0005)$ \\
\hline $\mathrm{N}$ & 95617 & 95617 & 55903 \\
Controls & $\checkmark$ & $\checkmark$ & $\checkmark$ \\
Seller FE & & & $\checkmark$ \\
\hline \hline
\end{tabular}

Notes: This table presents our results from regressing message success onto a measure of seller experience. Sim $(m$, week 10) is the cosine similarity between a message and the set of week 10 messages excluding sellers who sent more than 11 messages. All models include our main set of controls: time trend; $\ln ($ ask price); category by condition fixed effects; day of week, precipitation, holiday dummies, and the temperature. Likewise, all models drop sellers sending more than 10 messages. Model (3) includes seller fixed effects. Robust standard errors are reported in parentheses and ${ }^{*}$ denotes statistical significance at $\alpha=0.05$. 